\title{
1-Hydroxyethylidene-1,1-diphosphonic Acid (HEDP) as a Corrosion Inhibitor of AISI 304 Stainless Steel in a Medium Containing Chloride and Sulfide Ions in the Presence of Different Metallic Cations
}

\author{
Juliana Panceri Franco, Josimar Ribeiro* \\ Laboratório de Pesquisa e Desenvolvimento em Eletroquímica, Departamento de Química do Centro de Ciências Exatas da \\ Universidade Federal do Espírito Santo, Vitória, Brazil \\ Email: *josimar.ribeiro@ufes.br
}

How to cite this paper: Franco, J.P. and Ribeiro, J. (2020) 1-Hydroxyethylidene1,1-diphosphonic Acid (HEDP) as a Corrosion Inhibitor of AISI 304 Stainless Steel in a Medium Containing Chloride and Sulfide Ions in the Presence of Different Metallic Cations. Advances in Chemical Engineering and Science, 10, 225-257.

https://doi.org/10.4236/aces.2020.103017

Received: May 28, 2020

Accepted: July 28, 2020

Published: July 31, 2020

Copyright $\odot 2020$ by author(s) and Scientific Research Publishing Inc. This work is licensed under the Creative Commons Attribution International License (CC BY 4.0).

http://creativecommons.org/licenses/by/4.0/ (c) (i) Open Access

\begin{abstract}
The novelty of this paper is the analysis in a medium containing sulfide ion due to the generation of this ion in petroleum industries, in the refining stage (the sulfide ion is also present on the produced water). The performance of 1-hydroxyethylidene-1,1-diphosphonic acid inhibitor (HEDP) was investigated by potentiodynamic polarization, electrochemical impedance spectroscopy, and weight loss measurements in a dissolution of AISI 304 stainless steel immersed in a solution containing chloride and sulfide ions. The protection of the stainless was increased with the addition of divalent cations $\left(\mathrm{Ca}^{2+}\right.$, $\mathrm{Zn}^{2+}$, and $\left.\mathrm{Mg}^{2+}\right)$. Potentiodynamic polarization studies have shown that the inhibitor alone has anodic protection, but the addition of $\mathrm{Ca}^{2+}\left(10 \mathrm{mg} \cdot \mathrm{L}^{-1}\right)$ favors the cathodic protection, and the addition of $\mathrm{Zn}^{2+}\left(20 \mathrm{mg} \cdot \mathrm{L}^{-1}\right)$ and $\mathrm{Mg}^{2+}$ (10 mg. $\left.\mathrm{L}^{-1}\right)$ mixed-type is observed. Electrochemical impedance spectroscopy was performed at three distinct potentials: -0.3 [V vs. SCE], $E_{\text {corr }}[\mathrm{V} v s . \mathrm{SCE}$ ], and 0.1 [V vs. SCE]. This revealed that calcium is responsible for favoring the formation of the film and the other elements (zinc and magnesium) favor the stabilization of the protective film. Scanning electron microscopy analysis revealed that the addition of cations provided the adsorption of HEDP on the metal surface. Weight loss results showed that the presence of zinc in a solution containing HEDP favored greater inhibitor efficiency $\left(\mathrm{Zn}^{2+} \eta_{\mathrm{m}}=85.2 \%\right.$ and for $\left.\mathrm{Mg}^{2+} \eta_{\mathrm{m}}=70.4 \%\right)$.
\end{abstract}




\section{Keywords}

AISI 304 Stainless Steel, HEDP, Corrosion Inhibitor, Chloride and Sulfide Ions, Electrochemical Impedance Spectroscopy

\section{Introduction}

Stainless steel is utilized in aggressive environments due to the formation of a passive film [1]. The chemical composition of this steel consists of $\mathrm{Fe}$ and $\mathrm{Cr}$. The presence of $\mathrm{Cr}$ guarantees the formation of the protective film composed of chromium oxide which protects the material and minimizes pitting corrosion, increasing its industrial applicability [2] [3].

Metal corrosion is defined as the destructive attack of metal material by chemical or electrochemical action on the medium, leading to consequences such as high-cost maintenance, material loss, and product contamination [4].

AISI 304 austenitic stainless steel is utilized in the chemical, petroleum, pulp and paper, aerospace, and food industries [5] [6]. The material can suffer localized corrosion, stress corrosion, and crack corrosion. These processes occur due to possible film defects that are preferred sites for nucleation [6]. Besides environmental factors such as the presence of chloride and sulfide ions, the presence of inclusions in the microstructure, especially inclusions consisting of $\mathrm{MnS}$, leads to pitting corrosion [7].

Inhibitory substances are added to reduce corrosion in materials. Their main advantage is that they protect the equipment by increasing its durability [8]. The most commonly used inhibitors are organic inhibitors and their efficiency is related to the presence of heteroatoms such as $\mathrm{N}, \mathrm{S}, \mathrm{P}$, and $\mathrm{O}$, and $\pi$ bonds and groups with polar functions such as $-\mathrm{CN},-\mathrm{NO}_{2},-\mathrm{OH},-\mathrm{OCH}_{3},-\mathrm{COOH},-\mathrm{COOC}_{2} \mathrm{H}_{5},-\mathrm{NH}_{2}$, $-\mathrm{CONH}_{2}$ [9] [10] [11] [12]. Inhibitor efficiency is increased using molecules with planar geometries as they have greater contact with the metal surface, ensuring greater adsorption [10]. 1-Hydroxyethylidene-1,1-diphosphonic acid (HEDP) has a P-C-P bond and is classified as an organic phosphonic acid [13]. The HEDP is a commercial inhibitor and its molecular structure consists of a central carbon atom and two phosphonic acidic groups, which are linked to the central atom, together with a hydroxyl group and a methyl group [14] (see Figure S1 in the supplementary material). This inhibitor forms complexes with divalent cations such as $\mathrm{Ca}^{2+}, \mathrm{Zn}^{2+}, \mathrm{Mg}^{2+}, \mathrm{Cu}^{2+}, \mathrm{Fe}^{2+}, \mathrm{Ni}^{2+}, \mathrm{Cd}^{2+}$ and $\mathrm{Pb}^{2+}$ [15] [16].

The performance of the HEDP inhibitor has been studied by Kármán et al. [17]. Using carbon steel immersed in a medium containing $0.5 \mathrm{~mol} \cdot \mathrm{L}^{-1} \mathrm{NaClO}_{4}$, $3 \times 10^{-4} \mathrm{~mol} \cdot \mathrm{L}^{-1} \mathrm{HEDP}$, and $3 \times 10^{-4} \mathrm{~mol} \cdot \mathrm{L}^{-1} \mathrm{Ca}\left(\mathrm{NO}_{3}\right)_{2}$, research showed that isolated HEDP has anodic protection. On the other hand, the addition of $\mathrm{Ca}^{2+}$ contributes to shifting the corrosion potential to more negative values. In a study by Award [12] on carbon steel immersed in a solution containing $3 \times 10^{-3} \mathrm{~mol} \cdot \mathrm{L}^{-1}$ $\mathrm{NaCl}$, it was observed that the presence of HEDP alone at a concentration of 70 
$\mathrm{mg} \cdot \mathrm{L}^{-1}$ accelerated the corrosive process. The addition of zinc at concentrations of $40-60 \mathrm{mg} \cdot \mathrm{L}^{-1}$ had an impact on the anodic reaction and inhibited corrosion. Recently, Yan et al. [15] studied the corrosion process on carbon steel immersed in a $3.5 \mathrm{wt} \% \mathrm{NaCl}$ solution, $8.2 \times 10^{-3} \mathrm{~mol} \cdot \mathrm{L}^{-1} \mathrm{HEDP}$, and $8.2 \times 10^{-3} \mathrm{~mol} \cdot \mathrm{L}^{-1}$ of $\mathrm{Zn}\left(\mathrm{NO}_{3}\right)_{2}$, they concluded that the presence of $\mathrm{Zn}^{2+}$ after 2 hours of immersion favored an inhibition between $93.4 \%$ and $99.3 \%$. In a study carried out with stainless steel, SS 41 , immersed in a medium containing $0.3 \% \mathrm{NaCl}$ by Sekine and Hirakawa [18], a maximum inhibitor efficiency at the concentration of 60 $\mathrm{mg} \cdot \mathrm{L}^{-1} \mathrm{HEDP}$ was verified with the addition of $40 \mathrm{mg} \cdot \mathrm{L}^{-1} \mathrm{ZnSO}_{4} \cdot 7 \mathrm{H}_{2} \mathrm{O}$. They concluded that the anodic region is protected by the HEDP inhibitor and the cathodic region by $\mathrm{Zn}^{2+}$, due to the formation of a $\mathrm{Zn}(\mathrm{OH})_{2}$ film. Other paper developed by Sekine et al. [19] with the AISI 304 stainless steel, indicated the importance of the presence of $\mathrm{Ni}$ and $\mathrm{Cr}$ on the steel composition for the formation of a protective film together with HEDP.

The $\mathrm{pH}$ influences the adsorption of the inhibitor on the metal surface. An investigation carried out by Awad and Turgoose [20] on mild steel, concluded that in the absence of chloride ions, a mixture consisting of HEDP-Zn showed protective characteristics at the $\mathrm{pH}$ range from 6.5 to 9.5. However, with a decrease of $\mathrm{pH}$ to 4.5 , adsorption is reduced due to the increase of free phosphonate. The effect of $\mathrm{Ca}^{2+}$ was observed by Mohammedi et al. [21], in an analysis of carbon steel immersed in a medium containing $1.7 \times 10^{-3} \mathrm{~mol} \cdot \mathrm{L}^{-1}$ HEDP, $1.7 \times 10^{-3} \mathrm{~mol} \cdot \mathrm{L}^{-1} \mathrm{NaCl}$ and $3.0 \times 10^{-3} \mathrm{~mol} \cdot \mathrm{L}^{-1} \mathrm{CaSO}_{4}$, and found that at $\mathrm{pH} 7.0$, the addition of $\mathrm{Ca}^{2+}$ increased inhibitor efficiency by up to $80 \%$. At $\mathrm{pH}$ 11 , the addition of this divalent cation did not favor the increase in inhibitor efficiency, i.e., indicating that this cation acts at low $\mathrm{pH}$.

The novelty of this paper is the analysis in a medium containing sulfide ion. The reduction of sulfate to sulfide by sulfate-reducing bacteria (SRB), occurs downhole in oil reservoirs, as well as in above-ground facilities. This process is unwanted because its toxicity presents a potential danger to human health and because its presence increases corrosion of pipelines and other steel infrastructure [22] [23]. The investigation in a medium containing sulfide ion was also carried out due to the generation of this ion in petroleum industries, in the refining stage (the sulfide ion is also present on the produced water) [24] [25] [26].

In our study, potentiodynamic polarization (PDP) techniques, electrochemical impedance spectroscopy (EIS), and weight loss measurements were employed to verify the efficiency of the HEDP inhibitor on AISI 304 austenitic stainless steel immersed in a solution containing $3.5 \mathrm{wt} \% \mathrm{NaCl}, 1 \mathrm{mmol} \cdot \mathrm{L}^{-1} \mathrm{Na}_{2} \mathrm{~S}$. EIS is one of the most important techniques for studying the strength characteristics of the film formed on the metal surface, which provides information on the corrosive process [12].

Subsequently, an evaluation was performed of the effect of the addition of divalent cations, $\mathrm{Ca}^{2+}, \mathrm{Zn}^{2+}$, and $\mathrm{Mg}^{2+}$, ranging from $10 \mathrm{mg} \cdot \mathrm{L}^{-1}$ to $30 \mathrm{mg} \cdot \mathrm{L}^{-1}$, in a solution containing $50 \mathrm{mg} \cdot \mathrm{L}^{-1}$ of the inhibitor under investigation. The study 
was carried out to verify the performance of the presence of divalent cations with HEDP, on AISI 304 austenitic stainless steel immersed in an aggressive medium containing chloride and sulfide ions. Surface analysis after applied potential was also performed by Scanning Electron Microscopy (SEM) and Energy Dispersive X-Ray Spectroscopy (EDS).

\section{Experimental Part}

\subsection{Samples Preparations}

The samples were cut in an L-shape for electrochemical and morphological analysis. The cut was performed using a hand guillotine. The test area was 1.0 $\mathrm{cm}^{2}$, which was isolated with epoxy resin (Araldite ${ }^{\circledR}$ ).

For all investigations, the samples were wet sanded using silicon carbide sandpaper with grit sizes of 180,220,320,500, 800, and 1200 mesh. The sanded samples were cleaned with $97 \%$ ethanol and dried in hot air. They were subsequently polished using Arotec ${ }^{\circledR} 6 \mu \mathrm{m}, 3 \mu \mathrm{m}, 1 \mu \mathrm{m}$, and $1 / 4 \mu \mathrm{m}$ diamond paste to obtain a scratch-free specular surface. The samples were sanded and polished using an Arotec ${ }^{\circledR}$ polishing machine, the Aropol VV model.

\subsection{Solutions}

The solutions used in the electrochemical tests (Potentiodynamic Polarization and Electrochemical Impedance Spectroscopy) for the analysis of the efficiency of the HEDP inhibitor were composed of a mixture of $3.5 \mathrm{wt} \% \mathrm{NaCl} \mathrm{PA}$ (Dinâmica, Indaiatuba, SP, Brazil), $1 \mathrm{mmol} \cdot \mathrm{L}^{-1} \mathrm{Na}_{2} \mathrm{~S}$ PA (Impex, Diadema, SP, Brazil) and 20, 30, 50, and $100 \mathrm{mg} \cdot \mathrm{L}^{-1}$ HEDP (Polyorganic Technology, São Paulo, SP, Brazil). All the solutions were prepared using the ultrapure water (SARTORIUS mini Arium ${ }^{\circledR}$ with a resistivity of $18.2 \mathrm{M} \Omega \mathrm{cm}$ at $22^{\circ} \mathrm{C} \pm 3^{\circ} \mathrm{C}$ ).

The effects of calcium, zinc, and magnesium were investigated in a solution containing $3.5 \mathrm{wt} \% \mathrm{PA} \mathrm{NaCl} \mathrm{PA}, 1 \mathrm{mmol} \cdot \mathrm{L}^{-1} \mathrm{Na}_{2} \mathrm{~S}$ PA, and $50 \mathrm{mg} \cdot \mathrm{L}^{-1} \mathrm{HEDP}$, $\mathrm{CaCl}_{2} \mathrm{PA}$ (Dinâmica, Indaiatuba, SP, Brazil), $\mathrm{ZnCl}_{2}$ (97\%, Dinâmica, Indaiatuba, SP, Brazil), and $\mathrm{MgCl}_{2}$ PA (Synth, Diadema,SP,Brazil) with concentrations ranged from 10 to $30 \mathrm{mg} \cdot \mathrm{L}^{-1}$.

The $\mathrm{pH}$ of the solution was measured using the pocket-sized $\mathrm{pH}$ meter Isfetcom, S2K712 model. The $\mathrm{pH}$ of the solution in the absence of the inhibitor is 9.5 , in the presence of the inhibitor $\left(50 \mathrm{mg} \cdot \mathrm{L}^{-1}\right) 8.3$, in the presence of calcium $\left(10 \mathrm{mg} \cdot \mathrm{L}^{-1}\right) 5.9$, in the presence of zinc $\left(20 \mathrm{mg} \cdot \mathrm{L}^{-1}\right) 5.8$ and in the presence of magnesium $\left(10 \mathrm{mg} \cdot \mathrm{L}^{-1}\right)$ 6.4. The electrolytes were not stirred or heated. The temperature for all the measurements was $21^{\circ} \mathrm{C} \pm 3^{\circ} \mathrm{C}$. In order to obtain the real operation conditions, the oxygen dissolved in the solution was not removed.

\subsection{Optical Microstructural Characterizations}

The samples were prepared in bakelite phenolic resin by means of an Arotec ${ }^{\circledR}$ automatic mounting press, Pre Mi model. Then, the samples were electrolyzed per $30 \mathrm{~s}$, using a voltage of $6 \mathrm{~V}$ and in the presence of oxalic acid $10 \mathrm{wt} \%$, ac- 
cording to ASTM A262-15 [27]. Microstructural characterizations by optical microscopy were performed using a Nikon Inverted Optical Microscope, Eclipse MA 200 model.

\subsection{Scanning Electron Microscopy and Energy Dispersive X-Ray Spectroscopy Characterizations}

The microstructural characterizations of the samples under investigations were carried out using two different equipment: Scanning Electron Microscopy (SEM) coupled to the X-ray Dispersive Energy Spectrometer (EDS), Shimadzu ${ }^{\circledR}$ SS550 model microscope with voltage acceleration of $25 \mathrm{kV}$; and the microscope from Zeizz $^{\circledR}$, EVO I MA 10 model, and the Oxford Instruments model X-MaxN spectrometer. The data were obtained by AZtec 2.1a software. The voltage acceleration was $30 \mathrm{kV}$.

\subsection{Electrochemical Tests}

Electrochemical experiments were performed on an AUTOLAB 302 potentiostat/galvanostat equipped with Nova 2.1.1 software. A three-electrode cell configuration consisting of working electrode $\left(1.0 \mathrm{~cm}^{2}\right.$ AISI 304 stainless steel samples), a carbon counter electrode with dimensions of $6.76 \mathrm{~mm} \times 22.55$ $\mathrm{mm} \times 59.61 \mathrm{~mm}$, and a saturated calomel reference electrode (SCE- $\mathrm{Hg} / \mathrm{Hg}_{2} \mathrm{Cl}_{2}$ ) was used.

Open circuit potential $\left(E_{\mathrm{OC}}\right)$ was determined by employing a scan rate of 1 $\mathrm{mV} \cdot \mathrm{s}^{-1}$ over $3600 \mathrm{~s}$. Potentiodynamic Polarization (PDP) measurements were carried out over a potential range of $\pm 240 \mathrm{mV}$ around the $E_{\mathrm{OC}}$.

EIS measurements were carried out at three distinct potentials: $\mathrm{E} 1=$ corrosion potential $\left(E_{\text {corr }}[\mathrm{V} v s . \mathrm{SCE}]\right), \mathrm{E} 2=-0.3[\mathrm{~V} v s . \mathrm{SCE}]$ and $\mathrm{E} 3=0.1[\mathrm{~V} v s . \mathrm{SCE}]$ at the frequency range from $100 \mathrm{kHz}$ to $10 \mathrm{mHz}$, and the signal amplitude sine wave used was $E_{\text {rms }}$ (root mean square) $=5 \mathrm{mV}(\mathrm{p} / \mathrm{p})$ with 10 points per logarithmic decade using "single sine" mode. The simulation of the obtained data was performed in EIS Spectrum Analyzer Software using the Newton algorithm and the amplitude function. The electrical equivalent circuit used in the fit was $R_{\mathrm{s}}\left(C P E-R_{\mathrm{p}}\right)$ (see Figure $\mathrm{S} 2$ in the supplementary material), where $R_{\mathrm{s}}$ is the solution resistance, $R_{\mathrm{p}}$ is the polarization resistance, and $C P E$ is the constant phase element and is related to capacitive characteristics of the system. Data were adjusted with errors below $10 \%$ and chi-square at $10^{-3}$. Chi-square $\left(r_{\mathrm{c}}^{2}\right)$ is determined according to Equation (1) [28], where $Z_{i}^{\prime}$ is the real and $Z_{i}^{\prime \prime}$ is the imaginary impedance values obtained from the EIS experimental data; $Z_{i, \text { calc }}^{\prime}$ is the real and $Z_{i, \text { calc }}^{\prime \prime}$ is the imaginary impedance values calculated at the fitting of the curve. This free software was obtained from the website:

http://www.abc.chemistry.bsu.by/vi/analyser/ [28].

$$
r_{\mathrm{c}}^{2}=\sum_{i=1}^{N} \frac{\left(Z_{i}^{\prime}+Z_{i, \text { calc }}^{\prime}\right)^{2}-\left(Z_{i}^{\prime \prime}+Z_{i, \text { calc }}^{\prime \prime}\right)^{2}}{\left(Z_{i}^{\prime}\right)^{2}+\left(Z_{i}^{\prime \prime}\right)^{2}}
$$

The inhibitor efficiency was calculated by Equation (2) [29], where $\eta_{\mathrm{E}}$ is the 
inhibitor efficiency, $R_{\mathrm{p}}$ is the polarization resistance in the presence of the inhibitor, and $R_{\mathrm{p}}^{\prime}$ is the polarization resistance in the absence of the inhibitor.

$$
\eta_{\mathrm{E}}(\%)=\frac{R_{\mathrm{p}}-R_{\mathrm{p}}^{\prime}}{R_{\mathrm{p}}} * 100
$$

\subsection{Weight Loss Measurements}

Weight loss measurements were based on ASTM G31-72 [30]. The AISI 304 stainless steel samples were immersed in a $50 \mathrm{~mL}$ volume of the solutions that obtained the best result in the electrochemical tests for 3 months. After the soaking time, they were washed and treated for pickling. The steel pickling process was performed according to ASTM A380/A380M-17 [31] using a 20\% v/v nitric acid solution. Following the pickling process, the samples were washed, dried, and weighed. The corrosion rate $\left(C_{\mathrm{R}}\right)$ was calculated according to Equation (3) [30], where $K$ : constant $\left(8.76 \times 10^{4} \mathrm{~mm} \cdot\right.$ year $\left.^{-1}\right)$; $W$ : weight loss (g); $A$ : sample area $\left(\mathrm{cm}^{2}\right)$; $T$ : immersion time $(\mathrm{h})$; and $D$ : sample density $\left(8.0 \mathrm{~g} \cdot \mathrm{cm}^{-3}\right)$. The surface coverage $(\theta)$ and weight loss efficiency $\left(\eta_{\mathrm{m}}\right)$ calculations were performed according to Equations (4) and (5), respectively, where $C_{\mathrm{R} 0}$ is the corrosion rate in the absence of the inhibitor and $C_{\mathrm{RI}}$ is the corrosion rate in the presence of the inhibitor [32].

$$
\begin{gathered}
C_{\mathrm{R}}=\frac{K * W}{A * T * D} \\
\theta=\frac{C_{\mathrm{R} 0}-C_{\mathrm{RI}}}{C_{\mathrm{R} 0}} \\
\eta_{\mathrm{m}}(\%)=\frac{C_{\mathrm{R} 0}-C_{\mathrm{RI}}}{C_{\mathrm{R} 0}} * 100
\end{gathered}
$$

\section{Results and Discussion}

\subsection{Microstructural Characterization before Potentiodynamic Polarization Tests}

In the optical microscopy image of the AISI 304 stainless steel there is a microstructure of recrystallized austenite grains and annealing twins, which are characterized by parallel bands in contrast to the grains [33]. The inclusions are points susceptible to dissolution during corrosion and allow the formation of a corrosion cell within the metal and will act as an anode, cathode, or be inert, according to its potential [34] [35]. For these points, EDS analysis was performed and the spectra showed the presence of inclusions composed of $\mathrm{Mn}$ and S which favors the material corrosion process, as they are preferential sites for nucleation and pit growth [30] (see Figure S3 and Figure S4 in the supplementary material).

\subsection{Potentiodynamic Polarization Tests}

Potentiodynamic polarization curves for AISI 304 stainless steel in a solution containing $3.5 \mathrm{wt} \% \mathrm{NaCl}, 1 \mathrm{mmol} \cdot \mathrm{L}^{-1} \mathrm{Na}_{2} \mathrm{~S}$ in the absence and presence of the 
HEDP inhibitor at concentrations of $20,30,50$, and $100 \mathrm{mg} \cdot \mathrm{L}^{-1}$ are shown in Figure 1. Figure 1(a) shows that the addition of the inhibitor favored a change of corrosion potential $\left(E_{\text {corr }}\right)$ to more positive potentials, indicating that the HEDP inhibitor is an anodic type controlling the oxidation reaction. The same result was observed by Kármán et al. [17], Sekine et al. [19] and Salasi and Shahrabi [36] indicating that the complex is formed on the metallic surface on the anode sites.

The potentiodynamic polarization results shown in Figure 1 indicated that in the presence of the inhibitor there is a reduction in $j_{\text {corr }}$ values up to the $50 \mathrm{mg} \cdot \mathrm{L}^{-1}$ inhibitor concentration, suggesting a lower electron flow from the anodic region to the cathodic region and favoring greater protection of the material in the aggressive medium containing chloride and sulfide ions. On the other hand, an increase in $j_{\text {corr }}$ is observed at a concentration of $100 \mathrm{mg} \cdot \mathrm{L}^{-1}$, indicating an increase in the corrosion rate. According to Sekine et al. [19] the higher concentration of the inhibitor, culminate in an increase in the rate of corrosion, due to an excess of HEDP ions dissolved in the solution. The excess of HEDP leads to the formation of a soluble complex consisting of HEDP-iron capable of preventing passivation [20]. Thus, one can infer that, the best inhibitor concentration that favored greater corrosion inhibition is $50 \mathrm{mg} \cdot \mathrm{L}^{-1}$.

In order to increase the efficiency of the corrosive process and favor a greater stabilization of the surface formed film, the effects of the addition of $\mathrm{Ca}^{2+}, \mathrm{Zn}^{2+}$, and $\mathrm{Mg}^{2+}$ in a solution containing $50 \mathrm{mg} \cdot \mathrm{L}^{-1} \mathrm{HEDP}$ were studied.

The addition of calcium in a solution containing chloride and sulfide ions did not produce a very significant effect when compared to a solution containing only $50 \mathrm{mg} \cdot \mathrm{L}^{-1} \mathrm{HEDP}$, as shown in Figure $1(\mathrm{~b})$. The addition of this cation at a concentration of $10 \mathrm{mg} \cdot \mathrm{L}^{-1}$ provided an increased inhibitory effect on AISI 304 stainless steel due to a slight lowering of $j_{\text {corr }}$ value, as indicated in Figure 1 (b) and may be related to a greater blockage of active sites consisting of manganese sulfide, present in the sample before the potentiodynamic polarization tests (see the SEM-EDS analysis in the Figure S4 in the supplementary material). There is a slight decrease in the cathodic current density confirming that $\mathrm{Ca}^{2+}$ promotes the oxygen reduction reaction, this behavior was also verified by Karmán et al. [17].

Potentiodynamic polarization curves with the addition of zinc are shown in Figure $1(c)$. Through analyzing the PDP curves, it was observed that the addition of $\mathrm{Zn}^{2+}$ displaced the corrosion potential to low $E_{\text {corr }}$-values and decrease on $j_{\text {corr }}$ when compared to the presence of $50 \mathrm{mg} \cdot \mathrm{L}^{-1} \mathrm{HEDP}$. This behavior was also verified by Yan et al. [15] in a study performed on cold-rolled steel immersed in a medium containing $0.0082 \mathrm{~mol} \cdot \mathrm{L}^{-1} \mathrm{HEDP}$ and $0.0082 \mathrm{~mol} \cdot \mathrm{L}^{-1} \mathrm{zinc}$ nitrate and by Award [12] in a carbon steel study using a medium containing $0.003 \mathrm{~mol} \cdot \mathrm{L}^{-1}$ $\mathrm{Cl}^{-}$.

Figure 1(d) shows that the addition of magnesium did not cause a significant change in the $50 \mathrm{mg} \cdot \mathrm{L}^{-1} \mathrm{HEDP}$ PDP curves. It was found that on the three $\mathrm{Mg}$ 

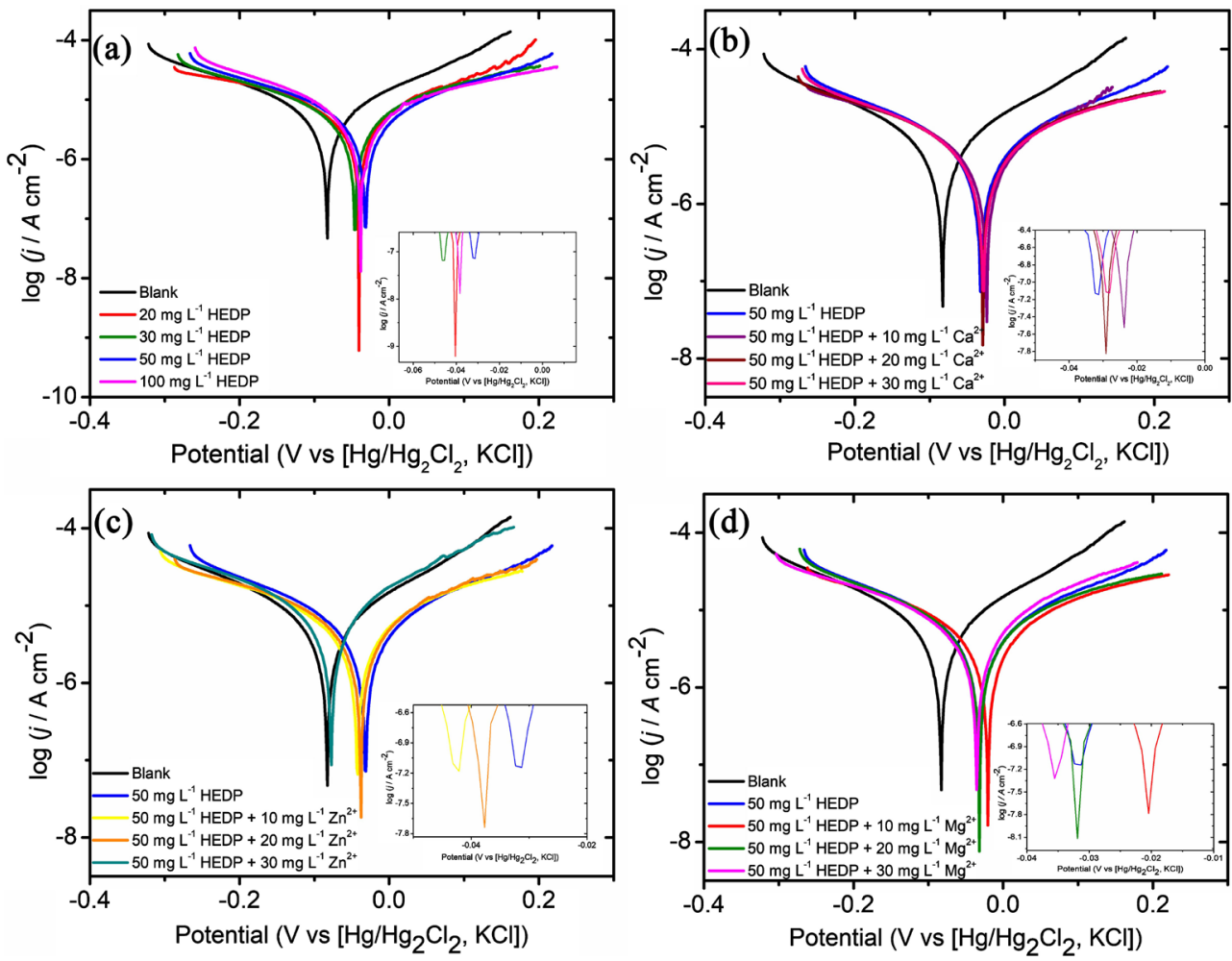

Figure 1. (a) Potentiodynamic polarization curves of AISI 304 stainless steel in a medium containing $3.5 \mathrm{wt} \% \mathrm{NaCl}, 1 \mathrm{mmol} \cdot \mathrm{L}^{-1} \mathrm{Na}_{2} \mathrm{~S}$, in the absence and presence of the HEDP inhibitor at 20, 30, 50 and $100 \mathrm{mg} \cdot \mathrm{L}^{-1}$ concentrations; (b) $\mathrm{CaCl}_{2}$ at 10,20 and $30 \mathrm{mg} \cdot \mathrm{L}^{-1}$ concentrations in the presence of $50 \mathrm{mg} \cdot \mathrm{L}^{-1} \mathrm{HEDP}$; (c) $\mathrm{ZnCl}_{2}$ at 10,20 and $30 \mathrm{mg} \cdot \mathrm{L}^{-1}$ concentrations in the presence of 50 $\mathrm{mg} \cdot \mathrm{L}^{-1} \mathrm{HEDP}$; (d) $\mathrm{MgCl}_{2}$ at 10,20 and $30 \mathrm{mg} \cdot \mathrm{L}^{-1}$ concentrations in the presence of $50 \mathrm{mg} \cdot \mathrm{L}^{-1}$ HEDP and scan rate of $1 \mathrm{mVs}^{-1}$. Inserts show the potential for corrosion.

concentrations investigated, there was no substantial variation of $E_{\text {corr }}$. However, when comparing the cathodic and anodic polarization curves, one can verify a greater variation in the cathodic current density, when compared with the presence of $50 \mathrm{mg} \cdot \mathrm{L}^{-1} \mathrm{HEDP}$, suggesting that this mixture acts mainly as a cathodic-type inhibitor [37]. The smallest $j_{\text {corr }}$ was identified by the addition of 10 $\mathrm{mg} \cdot \mathrm{L}^{-1} \mathrm{Mg}^{2+}$, indicating a greater blocking of the active sites and consequently a lower flow of electrons from the anodic region to the cathodic region. Smaller $j_{\text {corr }}$ were observed with the addition of zinc and magnesium, suggesting that in the presence of these divalent cations a hydroxide film of these cations can be formed in the cathodic area and facilitates adsorption of the inhibitor in the anodic area.

\subsection{Electrochemical Impedance Spectroscopy, EIS}

The sample surface consists of metal and a protective film, which due to its chemical composition is generally not evenly distributed, thus resulting in discontinuities. The film is the cathode area and the discontinuities are the anodic area. Thus, the EIS analysis was performed on three distinct potentials: $-0.3[\mathrm{~V}$ vs. SCE], $E_{\text {corr }}[\mathrm{V} v s . \mathrm{SCE}]$, and 0.1 [V vs. SCE]. Being that, two potentials far 
away to the $E_{\text {corr }}(-0.3[\mathrm{~V} v s . \mathrm{SCE}]$ and $0.1[\mathrm{~V} v s . \mathrm{SCE}])$ were performed to verify at which inhibitor concentrations the samples would present a more homogeneous film formation. Complex plane impedance $(a, b, c)$ and Bode $(d, e, f)$ plots obtained for the three distinct potentials are shown in Figure 2.

Complex plane impedance plots have the same shape as a single deformed semicircle for all the potentials investigated, indicating that the corrosion reaction in the AISI 304 stainless steel was controlled by the behavior of the double layer and the charge transfer process [38]. Moreover, it can see that the optimal inhibitor concentration to favor a surface containing a longer protective film was $100 \mathrm{mg} \cdot \mathrm{L}^{-1}$ for the -0.3 [V vs. SCE] and $30 \mathrm{mg} \cdot \mathrm{L}^{-1}$ for the others potentials ( $E_{\text {corr }}$
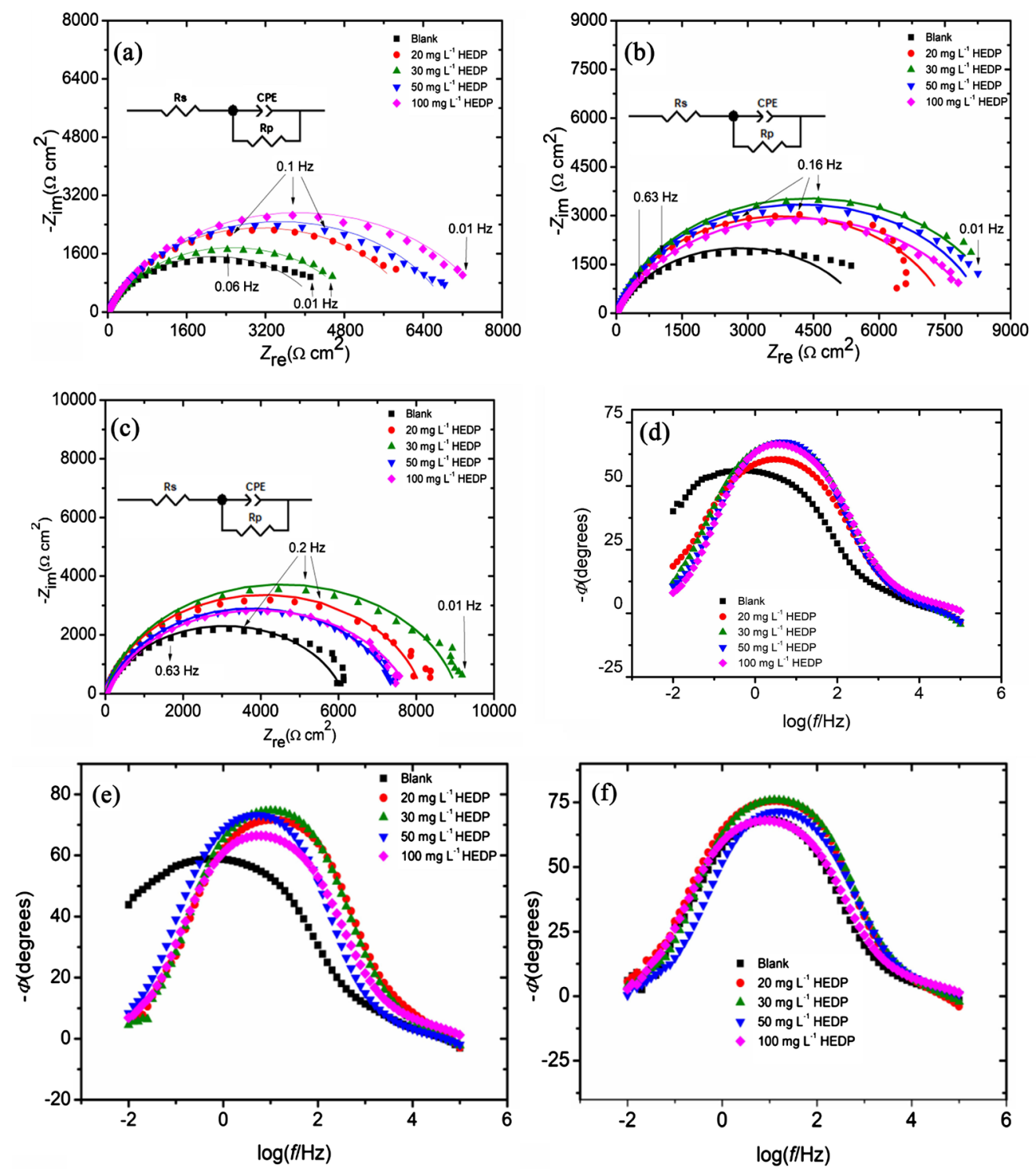

Figure 2. Complex plane impedance plots (a) -0.3 [V vs. SCE], (b) $E_{\text {corr }}[\mathrm{V} v s . \mathrm{SCE}]$ and (c) 0.1 [V vs. $\mathrm{SCE}$ ] and Bode plots (d) -0.3 [V vs. SCE], (e) $E_{\text {corr }}[\mathrm{V} v s$. SCE] and (f) 0.1 [V vs. SCE], in a medium containing $3.5 \mathrm{wt} \% \mathrm{NaCl}, 1 \mathrm{mmol} \cdot \mathrm{L}^{-1} \mathrm{Na}_{2} \mathrm{~S}$, in the absence and presence of HEDP inhibitor at concentrations of $20,30,50$ and $100 \mathrm{mg} \cdot \mathrm{L}^{-1}$ (where the line represents the fitting of the curves obtained in the data simulation). 
[V vs. SCE], and 0.1 [V vs. SCE]). One could infer this due to higher $Z_{\mathrm{re}}$-values observed. This fact indicates that at those concentrations, the inhibitor acted more effectively in the region most prone to the corrosive process such as inclusions, discontinuities, and grain boundaries, creating a protective barrier and making the surface more homogeneous. Increased semicircle inclination is associated with increased resistance to the charge transfer process from metal to electrolyte [37].

The effect of calcium is verified in Figure 3 in the complex plane impedance plots obtained at -0.3 [V vs. SCE] (a), $E_{\text {corr }}[\mathrm{V} v s . \mathrm{SCE}](\mathrm{b})$, and 0.1 [V vs. SCE] (c). These results show that the addition of a lower calcium concentration (10 $\mathrm{mg} \cdot \mathrm{L}^{-1}$ ) ensures a greater $Z_{\mathrm{re}}$ range and, consequently, a higher $R_{\mathrm{p}}$ value. This observation is in agreement with the results found in the PDP technique and
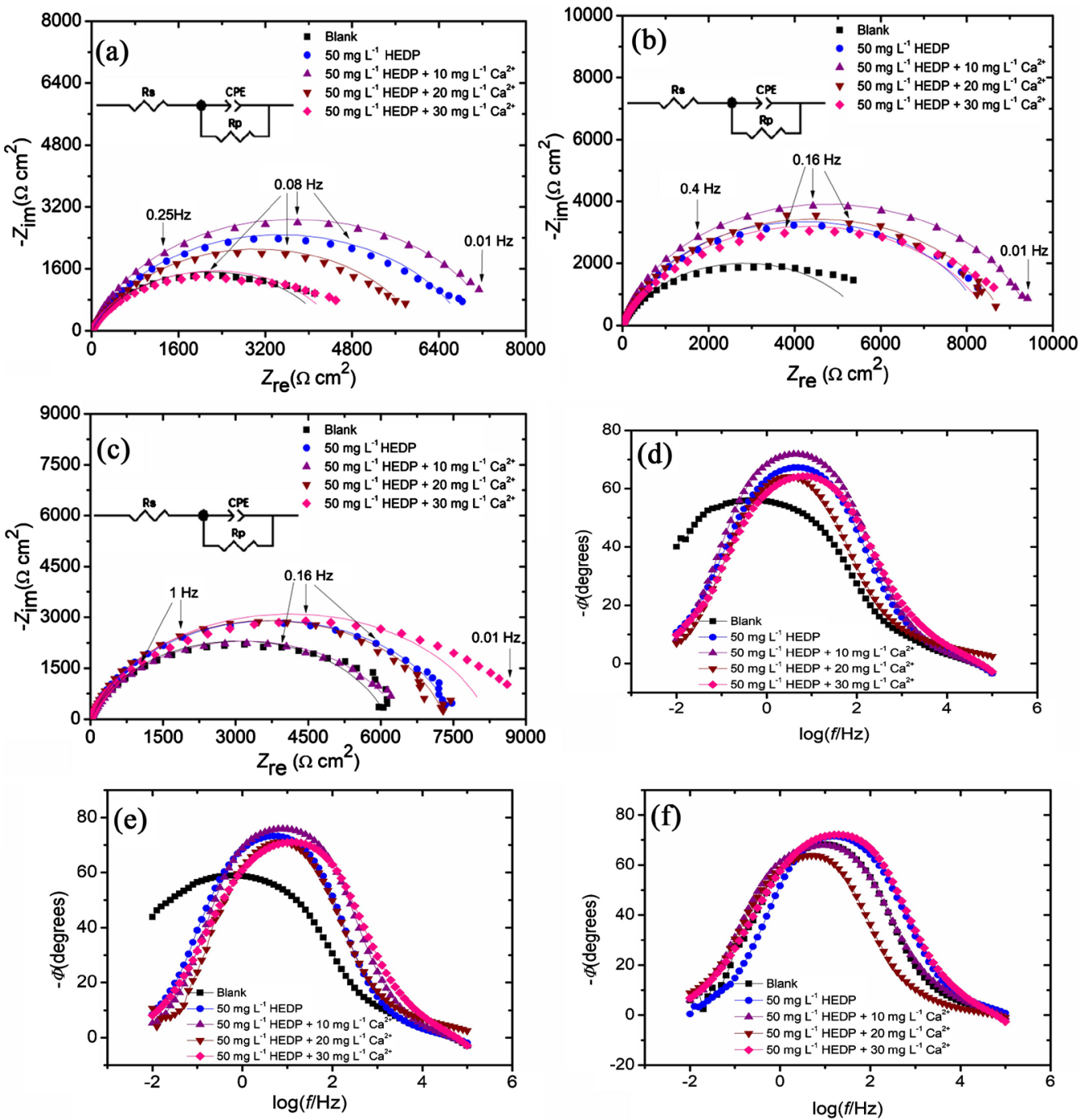

Figure 3. Complex plane impedance plots (a) -0.3 [V vs. SCE], (b) $E_{\text {corr }}[\mathrm{V} v s$. SCE] and (c) 0.1 [V vs. $\mathrm{SCE}$ ] and Bode plots (d) -0.3 [V vs. SCE], (e) $E_{\text {corr }}[\mathrm{V}$ vs. SCE] and (f) 0.1 [V vs. SCE], in a medium containing $3.5 \mathrm{wt} \% \mathrm{NaCl}, 1 \mathrm{mmol} \cdot \mathrm{L}^{-1} \mathrm{Na}_{2} \mathrm{~S}$, in the absence and presence of the HEDP inhibitor at a concentration of $50 \mathrm{mg} \cdot \mathrm{L}^{-1}$ and the addition of 10,20 and $30 \mathrm{mg} \cdot \mathrm{L}^{-1} \mathrm{CaCl}_{2}$ (where the line represents the curve fitting obtained in the data simulation). 
indicates that there has been a change in the kinetics of the corrosive process due to the formation of a protective film [39].

The adsorption of the inhibitor on the metal surface is influenced by $\mathrm{pH}$. Zenobi et al. [40] perform in-situ ATR-FTIR spectroscopy of HEDP in aqueous solution and observed a similar spectrum at $\mathrm{pH} 9.0$ and 8.0, only the $\mathrm{PO}_{3}^{2-}$ specie is protonated and, therefore, the phosphonic groups have different symmetry. At $\mathrm{pH}$ 7.0, bands of $\mathrm{HPO}_{3}^{-}$appear, in addition to the bands of $\mathrm{PO}_{3}^{2-}$. At $\mathrm{pH} 6.0$ and 5.0 the spectra show the same bands found for $\mathrm{pH} 7.0$, however, at $\mathrm{pH} 6.0$ there is a decrease in the bands corresponding to the $\mathrm{PO}_{3}^{2-}$ species and an increase in the $\mathrm{HPO}_{3}^{-}, \mathrm{POH}$ and $\mathrm{P}=\mathrm{O}$ bands. At $\mathrm{pH}$ 5.0, there was an increase in the intensity of the bands of the protonated species.

The $\mathrm{pH}$ measured for the absence of the inhibitor was 9.5 and for the addition of $50 \mathrm{mg} \cdot \mathrm{L}^{-1} \mathrm{HEDP}, 8.3$. The addition of $10 \mathrm{mg} \cdot \mathrm{L}^{-1} \mathrm{Ca}^{2+}$, which provided the best electrochemical results, shifted the $\mathrm{pH}$ to the value of 5.9. The adsorption of the inhibitor occurs by the union of the ligand with the divalent cation in the $\mathrm{PO}_{3}^{2-}$ species [29], however, in the $\mathrm{pH}$ range from 8.0 to 9.0, only the $\mathrm{PO}_{3}^{2-}$ specie is deprotonated [40], making the adsorption difficult. With the decrease in $\mathrm{pH}$, with the addition of $\mathrm{Ca}^{2+}$, in the range of $6.0-5.0$, there is a reduction of the $\mathrm{PO}_{3}^{2-}$ bands and the appearance of new bands [40] it is suggested that in this concentration there was an increase of protective film, due to a greater transport of the inhibitor to the metal surface.

According to Deluchat et al. [16] HEDP has the ability to complex with $\mathrm{Ca}^{2+}$ in a $\mathrm{pH}$ range of $5.5-7.0$. However, in the same $\mathrm{pH}$-range, it has a greater affinity for $\mathrm{Fe}^{2+}$. This indicates that $\mathrm{Ca}^{2+}$ facilitated the transport of HEDP to the metal surface, but did not favor the formation of a hydroxide film with protective characteristics. If one takes into account that the corrosion process occurs much more pronounced in an acidic environment, the change in $\mathrm{pH}$ observed from basic $\mathrm{pH}$ to acidic $\mathrm{pH}$, the system became much more aggressive, however, when observing that even at this acidic $\mathrm{pH}$ the inhibitor acted to protect the specimen by inhibiting the corrosive process. In this way, one can infer that the inhibition efficiency is much greater in the presence of inhibitor than without the inhibitor.

Figure 4 shows the effect of a zinc addition on the complex plane impedance plots at -0.3 [V vs. SCE] (a), $E_{\text {corr }}[\mathrm{V} v s . \mathrm{SCE}]$ (b), and 0.1 [V vs. SCE] (c). At potential -0.3 [V vs. SCE] (Figure 4(a)), it is observed that the addition of $\mathrm{Zn}$ did not contribute to the formation a protective film because it observed the larger deformed semicircle at $50 \mathrm{mg} \cdot \mathrm{L}^{-1}$ HEDP concentration in the absence of zinc cations. At $E_{\text {corr }}$ [V vs. SCE] (Figure 4(b)), the addition of $\mathrm{Zn}$ was positive for the protection of the steel surface from the attack of chloride and sulfide ions present in the solution. This was confirmed by an increase in deformed semicircle diameter at $10 \mathrm{mg} \cdot \mathrm{L}^{-1}$ and $20 \mathrm{mg} \cdot \mathrm{L}^{-1}$ concentrations. A study by Miao, Wang, and $\mathrm{Hu}$ [29] suggest that in the presence of $\mathrm{Zn}^{2+}$ in a bulk solution, HEDP- $\mathrm{Zn}^{2+}$ complexes are formed and diffused to the steel surface where it is converted to HEDP- $-\mathrm{Fe}^{2+}$. HEDP- $\mathrm{Fe}^{2+}$ is adsorbed to the anodic region according to Equation 

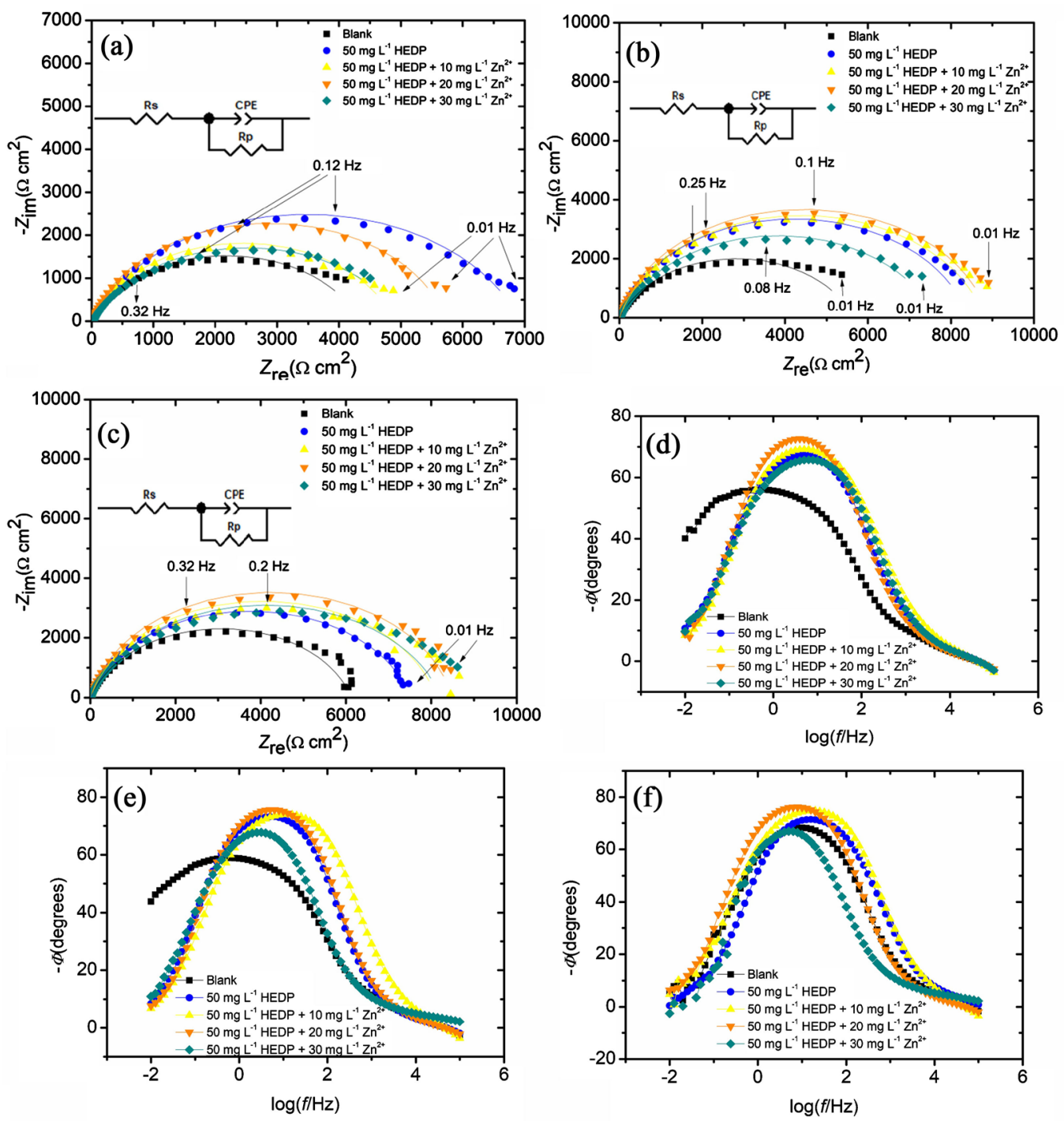

Figure 4. Complex plane impedance plots (a) -0.3 [V vs. SCE], (b) $E_{\text {corr }}$ [V vs. SCE] and (c) 0.1 [V vs. $\mathrm{SCE}]$ and Bode plots (d) -0.3 [V vs. SCE], (e) $E_{\text {corr }}$ [V vs. SCE] and (f) 0.1 [V vs. SCE], in a medium containing $3.5 \mathrm{wt} \% \mathrm{NaCl}, 1 \mathrm{mmol} \cdot \mathrm{L}^{-1} \mathrm{Na}_{2} \mathrm{~S}$, in the absence and presence of the HEDP inhibitor at a concentration of $50 \mathrm{mg} \cdot \mathrm{L}^{-1}$ and the addition of 10,20 and $30 \mathrm{mg} \cdot \mathrm{L}^{-1}$ of $\mathrm{ZnCl}_{2}$. (Where the line represents the curve fitting obtained in the data simulation)

(6). $\mathrm{Zn}^{2+}$ reacts with $\mathrm{OH}^{-}$from the cathodic reaction (Equation (7)) and forms zinc hydroxide (equation (8)) which is adsorbed to the cathodic region and has protective characteristics. Reznik et al. [41] also found a better result for the addition of $20 \mathrm{mg} \cdot \mathrm{L}^{-1} \mathrm{Zn}^{2+}$, in a work with the 1020 carbon steel, immersed in a medium containing $30 \mathrm{mg} \cdot \mathrm{L}^{-1} \mathrm{Cl}^{-}$and $50 \mathrm{mg} \cdot \mathrm{L}^{-1} \mathrm{HEDP}$ and concluded that the addition of $\mathrm{Zn}^{2+}$ was conducive to a greater formation of $\mathrm{Zn}(\mathrm{OH})_{2}$ and its deposition on cathodic sites, delaying the corrosive process.

The $\mathrm{pH}$ found for the presence of $\mathrm{Zn}^{2+}$ is similar to that found for $\mathrm{Ca}^{2+}$. $\left(\left[\mathrm{Zn}^{2+}\right]=20 \mathrm{mg} \cdot \mathrm{L}^{-1}\right.$, the $\left.\mathrm{pH}=5.8\right)$. In the range of $\mathrm{pH}$ from 5.5 to 7.0 , the $\mathrm{Zn}^{2+}$ ions can complex with HEDP, it already is verified by Deluchut et al. [16] that $\mathrm{Zn}^{2+}$ has a greater affinity to this inhibitor. This fact justifies greater protection 
for AISI 304 stainless steel in the presence of zinc, due to the formation and adsorption of a $\mathrm{Zn}(\mathrm{OH})_{2}$ film on cathodic sites.

$$
\begin{gathered}
\text { HEDP- } \mathrm{Zn}^{2+}+\mathrm{Fe}(\mathrm{s}) \rightleftarrows \operatorname{HEDP}-\mathrm{Fe}^{2+}+\mathrm{Zn}^{2+}(\mathrm{aq}) \\
\mathrm{O}_{2}(\mathrm{~g})+2 \mathrm{H}_{2} \mathrm{O}(\mathrm{l})+4 \mathrm{e}^{-} \rightleftarrows 4 \mathrm{OH}^{-}(\mathrm{aq}) \\
\mathrm{Zn}^{2+}(\mathrm{aq})+2 \mathrm{OH}^{-}(\mathrm{aq}) \rightleftarrows \mathrm{Zn}(\mathrm{OH})_{2}(\mathrm{aq})
\end{gathered}
$$

Finally, at potential 0.1 [V vs. SCE] (Figure 4(c)), it is shown that for all $\mathrm{Zn}$ concentrations there was an increase in deformed semicircle diameters, demonstrating that this element favors stabilization of the protective film adsorbed to the cathodic region.

Figure 5 shows the effect of magnesium addition in the complex plane impedance
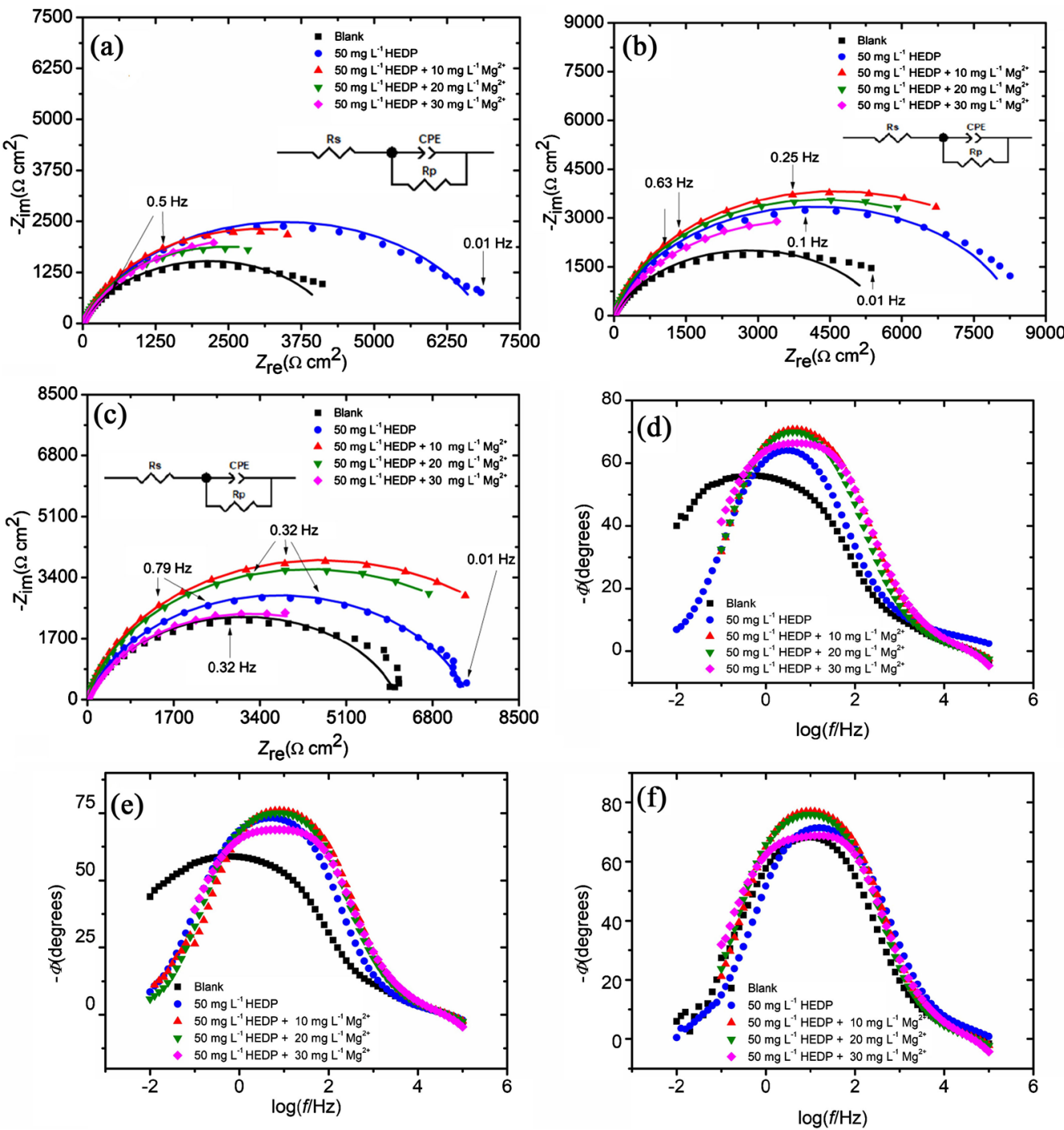

Figure 5. Complex plane impedance plots (a) -0.3 [V vs. SCE], (b) $E_{\text {corr }}[\mathrm{V} v s . \mathrm{SCE}]$ and (c) 0.1 [V vs. $\mathrm{SCE}]$ and Bode plots (d) -0.3 [V vs. SCE], (e) $E_{\text {corr }}[\mathrm{V} v s . \mathrm{SCE}]$ and (f) 0.1 [V vs. SCE], in a medium containing $3.5 \mathrm{wt} \% \mathrm{NaCl}, 1 \mathrm{mmol} \cdot \mathrm{L}^{-1} \mathrm{Na}_{2} \mathrm{~S}$, in the absence and presence of the HEDP inhibitor at a concentration of $50 \mathrm{mg} \cdot \mathrm{L}^{-1}$ and the addition of 10,20 and $30 \mathrm{mg} \cdot \mathrm{L}^{-1}$ of $\mathrm{MgCl}_{2}$. (Where the line represents the curve fitting obtained in the data simulation). 
plots obtained at the potential -0.3 [V vs. SCE] (a), $E_{\text {corr }}[\mathrm{V} v s$. SCE] (b) and 0.1 [V vs. SCE] (c). It is observed that the addition of magnesium results in a behavior similar to that of the addition of zinc, since both the cations, at the same potential -0.3 [V vs. SCE], do not indicate contribute to the formation of the protective film. Besides, it was observed that magnesium at $10 \mathrm{mg} \cdot \mathrm{L}^{-1}$ and 20 $\mathrm{mg} \cdot \mathrm{L}^{-1}$, favors the stabilization of the protective film due to a larger deformed semicircle at the $E_{\text {corr }}[\mathrm{V} v s . \mathrm{SCE}]$ and at the potential 0.1 [V vs. SCE]. The increase of the deformed semicircle indicates a greater inhibition of the corrosive process induced by the presence of the inhibitor [42]. The increase in semicircle inclination may be linked to the formation of an HEDP- $\mathrm{Mg}^{2+}$ complex in bulk solution which is transported to the material surface where it is converted to HEDP-Fe ${ }^{2+}$ (Equation (9)) and adsorbed in the anodic region. $\mathrm{Mg}^{2+}$ reacts with $\mathrm{OH}^{-}$from the cathodic reaction (Equation (7)) and forms magnesium hydroxide (Equation (10)), which is adsorbed to the cathodic region. According to the EIS-results obtained, it suggests that the film is formed by magnesium hydroxide has protective characteristics. At $10 \mathrm{mg} \cdot \mathrm{L}^{-1} \mathrm{Mg}^{2+}$ concentration, the $\mathrm{pH}$ of the solution was 6.4, indicating that the formation of the protective film consisting of $\mathrm{Mg}(\mathrm{OH})_{2}$ occurs at a $\mathrm{pH}$ value higher than that found for the presence of $\mathrm{Ca}^{2+}$ and $\mathrm{Zn}^{2+}$.

$$
\begin{aligned}
& \text { HEDP-Mg }{ }^{2+}+\mathrm{Fe}(\mathrm{s}) \rightleftarrows \mathrm{HEDP}-\mathrm{Fe}^{2+}+\mathrm{Mg}^{2+}(\mathrm{aq}) \\
& \mathrm{Mg}^{2+}(\mathrm{aq})+2 \mathrm{OH}^{-}(\mathrm{aq}) \rightleftarrows \mathrm{Mg}(\mathrm{OH})_{2}(\mathrm{aq})
\end{aligned}
$$

Bode plot (Figure 2(d)) shows that the addition of the inhibitor favored an increase in phase angle. At concentrations of 30,50 , and $100 \mathrm{mg} \cdot \mathrm{L}^{-1}$ of HEDP, this value remained constant at approximately $-68.0^{\circ}$. When analyzing the Bode plots, in the absence of the inhibitor a greater frequency widening is found suggesting a surface covered by a more uniform protective film [43]. This larger widening is due to the presence of $\mathrm{Ni}$ found in the EDS spectra (Figure S4(b) in the supplementary material), which guarantees greater resistance to the corrosive process in austenitic stainless steel [4]. According to Sekine et al. [19], on AISI 304 stainless steel a film is formed on the metal surface consisting of $\mathrm{Ni}, \mathrm{Cr}$ and the HEDP inhibitor. In Bode plot (Figure 2(e)), the maximum phase angle achieved was $-76.0^{\circ}\left(30 \mathrm{mg} \cdot \mathrm{L}^{-1}\right)$. Phase angles closer to $-90.0^{\circ}$ indicate an increased inhibition of the corrosive process due to higher adsorption of inhibitor molecules on the metal surface [44].

Bode plot (Figure 2(f)) indicates that the maximum phase angle reached was $-77.3^{\circ}\left(30 \mathrm{mg} \cdot \mathrm{L}^{-1}\right)$. Compared with the results obtained in the -0.3 [V vs. SCE] and on the corrosion potential, an increase of the maximum phase angle is evidence, indicating that the addition of the inhibitor contributed to a more capacitive behavior of the steel. Bode plots in the presence of calcium revealed that the addition of this element does not favor stabilization of the formed film due to a phase angle increasing from $-73.0^{\circ}(-0.3[\mathrm{~V} v s . \mathrm{SCE}])$ to $-77.04^{\circ}$ ( $E_{\text {corr }}[\mathrm{V} v s$. $\mathrm{SCE}]$ ) and its subsequent decay to $-73.2^{\circ}(0.1$ [V vs. SCE]) (see Figures $3(\mathrm{~d})-(\mathrm{f}))$. 
It was exposed that the corrosive process of steel in a medium containing HEDP, chloride, sulfide, and $\mathrm{Zn}^{2+}$ ions involved only a time constant. There was also a widening of range the frequency at intermediate frequencies. The impedance at intermediate frequencies reflects the contribution of capacitance [15] indicating that the formation of a protective film with greater homogeneity occurred, creating a barrier to the corrosive process. Film stabilization is confirmed by increasing the phase angle from $-73.6^{\circ}$ ( -0.3 [ $\mathrm{V}$ vs. SCE] -Figure $4(\mathrm{~d}))$ to $-77.1^{\circ}\left(0.1\right.$ [V vs. SCE] -Figure $4(\mathrm{f})$ ) at concentration of $20 \mathrm{mg} \cdot \mathrm{L}^{-1}$ $\mathrm{Zn}^{2+}$. Phase angles close to $-90.0^{\circ}$ suggests a more capacitive system and occur in response to increase inhibitor adsorption on the metal surface. At 0.1 [ V vs. $\mathrm{SCE}]$, the maximum phase angle was displaced to lower frequencies, indicating that the corrosive process was softened [39].

Figure 5 also shows Bode plots at -0.3 [V vs. SCE] (d), $E_{\text {corr }}[\mathrm{V} v s . \mathrm{SCE}](\mathrm{e})$, and 0.1 [V vs. SCE] (f) in a medium containing chloride, sulfide, and HEDP inhibitor in the presence and absence of magnesium. It was shown that for all investigated concentrations a single peak was identified, demonstrating that the corrosive process of AISI 304 stainless steel in these conditions is influenced by the charge transfer process and capacitance of the electrical double layer [45]. As verified for the presence of $\mathrm{Zn}$, the stabilization of the film on the AISI 304 stainless steel surface in the presence of $\mathrm{Mg}$ is confirmed by the phase angle increase from $-71.9^{\circ}\left(-0.3[\mathrm{~V}\right.$ vs. SCE]-Figure $5(\mathrm{~d}))$ to $-78.3^{\circ}(0.1[\mathrm{~V}$ vs. $\mathrm{SCE}$ - Figure 5(f)), indicating an adsorption of the inhibitor molecule on the metal surface.

The impedance plots were analyzed by the equivalent electrical circuit described in Figure $S 2$ in the supplementary material and the results are shown in Table 1 . The capacitance of the electrical double layer $\left(C_{\mathrm{dl}}\right)$ was calculated according to equation 11 [46].

$$
C_{\mathrm{dl}}=\left[\operatorname{CPE}\left(R_{\mathrm{s}}^{-1}+R_{\mathrm{p}}^{-1}\right)^{n-1}\right]^{1 / n}
$$

As shown in Table 1 ( -0.3 [V vs. SCE]), $R_{\mathrm{p}}$ values increased with the addition of the inhibitor. This fact suggests the formation of a thicker film on the metal surface, which minimizes localized corrosion by the penetration of chloride and sulfide ions. In parameter $n$ and the CPE values, no significant variation was observed indicating that the corrosion mechanism at this potential is controlled by the charge transfer process [23]. Thus, it is indicated that at potentials below the corrosion potential the presence of the HEDP inhibitor provided the formation of a more uniform and adherent protective film, indicating greater protection for dissolution of the AISI 304 stainless steel at higher potentials. The maximum inhibitor efficiency $\left(n_{\mathrm{E}}=43.8 \%\right)$ achieved was $[\mathrm{HEDP}]=100 \mathrm{mg} \cdot \mathrm{L}^{-1}$.

At $E_{\text {corr }}[\mathrm{V} v s . \mathrm{SCE}]$, the addition of the inhibitor generated an increase in $R_{\mathrm{p}}$ values. This increase was observed at concentrations of $30 \mathrm{mg} \cdot \mathrm{L}^{-1}$ and $50 \mathrm{mg} \cdot \mathrm{L}^{-1}$ and is associated to the adsorption of the molecule on the material surface [39]. There is also a decrease in $C_{\mathrm{dl}}$ values, which may be related to a reduction in the 
Table 1. Parameters obtained by simulating Electrochemical Impedance Spectroscopy data for AISI 304 stainless steel at -0.3 [V vs. SCE], $E_{\text {corr }}[\mathrm{V} v s$. SCE] and 0.1 [V vs. SCE], in a medium containing 3.5\% wt $\% \mathrm{NaCl}, 1 \mathrm{mmol} \cdot \mathrm{L}^{-1} \mathrm{Na}_{2} \mathrm{~S}$ and HEDP inhibitor; 50 $\mathrm{mg} \cdot \mathrm{L}^{-1} \mathrm{HEDP}$ and the addition of 10,20 and $30 \mathrm{mg} \cdot \mathrm{L}^{-1} \mathrm{CaCl}_{2}, 50 \mathrm{mg} \cdot \mathrm{L}^{-1} \mathrm{HEDP}$ and the addition of 10, 20 and $30 \mathrm{mg} \cdot \mathrm{L}^{-1} \mathrm{ZnCl}_{2}$ and $50 \mathrm{mg} \cdot \mathrm{L}^{-1} \mathrm{HEDP}$ and the addition of 10,20 and $30 \mathrm{mg} \cdot \mathrm{L}^{-1} \mathrm{MgCl}_{2}$

\begin{tabular}{|c|c|c|c|c|c|c|}
\hline $\begin{array}{l}\text { Concentration } \\
\left(\mathrm{mg} \cdot \mathrm{L}^{-1}\right)\end{array}$ & $\begin{array}{c}R_{\mathrm{s}} \\
\left(\Omega \mathrm{cm}^{2}\right)\end{array}$ & $\begin{array}{c}R_{\mathrm{p}} \\
\left(\Omega \mathrm{cm}^{2}\right)\end{array}$ & $\begin{array}{c}C P E \\
\left(\mathrm{Fs}^{-(1-\mathrm{n})} \mathrm{cm}^{-2}\right)\end{array}$ & $n$ & $\begin{array}{c}C_{\mathrm{dl}} \\
\left(\mu \mathrm{F} \mathrm{cm}^{-2}\right)\end{array}$ & $\begin{array}{c}\eta_{\mathrm{E}} \\
(\%)\end{array}$ \\
\hline \multicolumn{7}{|l|}{$-0.3[\mathrm{~V} v s . \mathrm{SCE}]$} \\
\hline 0 HEDP & 7.96 & $4.34 \times 10^{3}$ & $4.10 \times 10^{-4}$ & 0.780 & 81.5 & -- \\
\hline 20 HEDP & 6.29 & $6.20 \times 10^{3}$ & $3.20 \times 10^{-4}$ & 0.810 & 74.6 & 30.0 \\
\hline 30 HEDP & 7.83 & $5.89 \times 10^{3}$ & $2.34 \times 10^{-4}$ & 0.800 & 48.4 & 26.3 \\
\hline 50 HEDP & 14.5 & $6.91 \times 10^{3}$ & $1.54 \times 10^{-4}$ & 0.790 & 30.4 & 37.2 \\
\hline 100 HEDP & 13.4 & $7.73 \times 10^{3}$ & $2.10 \times 10^{-4}$ & 0.780 & 40.0 & 43.8 \\
\hline $50 \mathrm{HEDP}+10 \mathrm{Ca}^{2+}$ & 8.11 & $7.45 \times 10^{3}$ & $2.50 \times 10^{-4}$ & 0.840 & 76.7 & 41.7 \\
\hline $50 \mathrm{HEDP}+20 \mathrm{Ca}^{2+}$ & 22.1 & $6.05 \times 10^{3}$ & $2.54 \times 10^{-4}$ & 0.780 & 58.8 & 28.3 \\
\hline $50 \mathrm{HEDP}+30 \mathrm{Ca}^{2+}$ & 7.69 & $4.55 \times 10^{3}$ & $3.47 \times 10^{-4}$ & 0.761 & 53.9 & 4.61 \\
\hline $50 \mathrm{HEDP}+10 \mathrm{Zn}^{2+}$ & 6.74 & $4.89 \times 10^{3}$ & $2.96 \times 10^{-4}$ & 0.810 & 68.8 & 11.2 \\
\hline $50 \mathrm{HEDP}+20 \mathrm{Zn}^{2+}$ & 8.84 & $5.72 \times 10^{3}$ & $2.84 \times 10^{-4}$ & 0.850 & 98.7 & 24.1 \\
\hline $50 \mathrm{HEDP}+30 \mathrm{Zn}^{2+}$ & 21.1 & $5.00 \times 10^{3}$ & $3.95 \times 10^{-4}$ & 0.763 & 89.2 & 13.2 \\
\hline $50 \mathrm{HEDP}+10 \mathrm{Mg}^{2+}$ & 9.72 & $6.04 \times 10^{3}$ & $2.14 \times 10^{-4}$ & 0.830 & 60.4 & 28.1 \\
\hline $50 \mathrm{HEDP}+20 \mathrm{Mg}^{2+}$ & 9.96 & $4.94 \times 10^{3}$ & $2.70 \times 10^{-4}$ & 0.830 & 80.3 & 12.1 \\
\hline $50 \mathrm{HEDP}+30 \mathrm{Mg}^{2+}$ & 7.04 & $5.82 \times 10^{3}$ & $3.51 \times 10^{-4}$ & 0.790 & 71.1 & 25.4 \\
\hline \multicolumn{7}{|l|}{$E_{\text {corr }}[\mathrm{V} v s . \mathrm{SCE}]$} \\
\hline 0 HEDP & 7.95 & $5.64 \times 10^{3}$ & $3.21 \times 10^{-4}$ & 0.790 & 65.6 & -- \\
\hline 20 HEDP & 7.32 & $7.57 \times 10^{3}$ & $1.17 \times 10^{-4}$ & 0.850 & 33.6 & 25.5 \\
\hline 30 HEDP & 7.68 & $8.77 \times 10^{3}$ & $1.10 \times 10^{-4}$ & 0.860 & 34.7 & 35.7 \\
\hline 50 HEDP & 10.1 & $8.80 \times 10^{3}$ & $2.05 \times 10^{-4}$ & 0.840 & 63.2 & 35.9 \\
\hline 100 HEDP & 13.3 & $8.23 \times 10^{3}$ & $1.56 \times 10^{-4}$ & 0.780 & 27.3 & 31.5 \\
\hline $50 \mathrm{HEDP}+10 \mathrm{Ca}^{2+}$ & 8.01 & $9.52 \times 10^{3}$ & $1.18 \times 10^{-4}$ & 0.880 & 45.6 & 40.7 \\
\hline $50 \mathrm{HEDP}+20 \mathrm{Ca}^{2+}$ & 21.0 & $8.89 \times 10^{3}$ & $9.56 \times 10^{-5}$ & 0.840 & 29.3 & 36.5 \\
\hline $50 \mathrm{HEDP}+30 \mathrm{Ca}^{2+}$ & 7.55 & $8.59 \times 10^{3}$ & $1.35 \times 10^{-4}$ & 0.810 & 26.8 & 34.3 \\
\hline $50 \mathrm{HEDP}+10 \mathrm{Zn}^{2+}$ & 6.67 & $8.80 \times 10^{3}$ & $1.26 \times 10^{-4}$ & 0.850 & 36.1 & 35.9 \\
\hline $50 \mathrm{HEDP}+20 \mathrm{Zn}^{2+}$ & 9.58 & $8.90 \times 10^{3}$ & $1.61 \times 10^{-4}$ & 0.880 & 66.5 & 36.6 \\
\hline $50 \mathrm{HEDP}+30 \mathrm{Zn}^{2+}$ & 20.4 & $7.62 \times 10^{3}$ & $2.65 \times 10^{-4}$ & 0.800 & 71.8 & 26.0 \\
\hline $50 \mathrm{HEDP}+10 \mathrm{Mg}^{2+}$ & 9.74 & $9.22 \times 10^{3}$ & $9.55 \times 10^{-5}$ & 0.880 & 36.9 & 38.8 \\
\hline $50 \mathrm{HEDP}+20 \mathrm{Mg}^{2+}$ & 9.94 & $8.67 \times 10^{3}$ & $1.15 \times 10^{-4}$ & 0.880 & 45.6 & 34.9 \\
\hline $50 \mathrm{HEDP}+30 \mathrm{Mg}^{2+}$ & 7.04 & $7.89 \times 10^{3}$ & $2.29 \times 10^{-4}$ & 0.810 & 50.7 & 28.5 \\
\hline \multicolumn{7}{|l|}{$0.1[\mathrm{~V} v s . \mathrm{SCE}]$} \\
\hline 0 HEDP & 8.97 & $6.12 \times 10^{3}$ & $1.00 \times 10^{-4}$ & 0.820 & 21.4 & -- \\
\hline
\end{tabular}




\section{Continued}

\begin{tabular}{ccccccc}
\hline $20 \mathrm{HEDP}$ & 7.77 & $8.15 \times 10^{3}$ & $6.42 \times 10^{-5}$ & 0.880 & 22.8 & 24.9 \\
$30 \mathrm{HEDP}$ & 7.68 & $9.06 \times 10^{3}$ & $7.81 \times 10^{-5}$ & 0.870 & 25.7 & 32.4 \\
$50 \mathrm{HEDP}$ & 14.1 & $7.49 \times 10^{3}$ & $5.84 \times 10^{-5}$ & 0.840 & 15.1 & 18.3 \\
$100 \mathrm{HEDP}$ & 13.3 & $7.82 \times 10^{3}$ & $1.21 \times 10^{-4}$ & 0.800 & 24.2 & 21.7 \\
$50 \mathrm{HEDP}+10 \mathrm{Ca}^{2+}$ & 9.92 & $6.37 \times 10^{3}$ & $1.91 \times 10^{-3}$ & 0.800 & 708 & 3.92 \\
$50 \mathrm{HEDP}+20 \mathrm{Ca}^{2+}$ & 20.6 & $7.31 \times 10^{3}$ & $7.08 \times 10^{-5}$ & 0.850 & 22.3 & 16.3 \\
$50 \mathrm{HEDP}+30 \mathrm{Ca}^{2+}$ & 7.48 & $8.23 \times 10^{3}$ & $1.03 \times 10^{-4}$ & 0.820 & 21.3 & 25.6 \\
$50 \mathrm{HEDP}+10 \mathrm{Zn}^{2+}$ & 6.64 & $8.10 \times 10^{3}$ & $9.56 \times 10^{-5}$ & 0.860 & 28.8 & 24.4 \\
$50 \mathrm{HEDP}+20 \mathrm{Zn}^{2+}$ & 9.90 & $8.47 \times 10^{3}$ & $1.22 \times 10^{-4}$ & 0.880 & 48.8 & 27.7 \\
$50 \mathrm{HEDP}+30 \mathrm{Zn}^{2+}$ & 7.48 & $8.23 \times 10^{3}$ & $1.03 \times 10^{-4}$ & 0.820 & 21.3 & 25.6 \\
$50 \mathrm{HEDP}+10 \mathrm{Mg}^{2+}$ & 9.74 & $9.20 \times 10^{3}$ & $7.37 \times 10^{-5}$ & 0.890 & 30.1 & 33.5 \\
$50 \mathrm{HEDP}+20 \mathrm{Mg}^{2+}$ & 9.91 & $8.72 \times 10^{3}$ & $8.91 \times 10^{-5}$ & 0.880 & 34.1 & 29.8 \\
$50 \mathrm{HEDP}+30 \mathrm{Mg}^{2+}$ & 6.99 & $6.41 \times 10^{3}$ & $1.71 \times 10^{-4}$ & 0.820 & 39.0 & 4.52 \\
\hline
\end{tabular}

dielectric constant and/or an increase in the thickness of the electrical double layer. The approximation of parameter $n$ close to 1.0 indicates that the electrical double layer formed on the metal surface resembles a pure capacitor [47].

At 0.1 [V vs. SCE], an increase in charge transfer resistance values ( $R_{\mathrm{p}}$-values) up to a concentration of $30 \mathrm{mg} \cdot \mathrm{L}^{-1}$ is observed, reaching a value of $9.06 \times 10^{3} \Omega$ $\mathrm{cm}^{2}$ (and $n_{\mathrm{E}}=32.4 \%$ ). This fact may be related to the presence of $\mathrm{Ni}$ in the chemical composition of AISI 304 stainless steel as responsible for the repassivation process of regions of the ruptured protective film. A higher adsorption of the inhibitor on the surface of the steel at concentration of $50 \mathrm{mg} \cdot \mathrm{L}^{-1}$ HEDP $+10 \mathrm{mg} \cdot \mathrm{L}^{-1} \mathrm{Ca}^{2+}$ is confirmed by the decrease in CPE, $C_{\mathrm{dl}}$, and an increase in $n$ at $E_{\text {corr }}[\mathrm{V} v s$. SCE] which means a reduction of the exposed steel area and consequently a thicker electrical double layer [9]. The destabilization of the film is sustained by the increase of the $C P E$ and $C_{\mathrm{dl}}$ value at 0.1 [V vs. SCE].

The non-contribution of the protective film formation $(-0.3$ [V vs. SCE]) in the presence of zinc is confirmed by the increase in $C_{\mathrm{dl}}$ and the decrease in $R_{\mathrm{p}}$ values at $E_{\text {corr }}\left[\mathrm{V} v s\right.$. SCE], there is a decrease in $C_{\mathrm{dl}}$ and an increase in parameter $n$ at concentrations of 10 and $20 \mathrm{mg} \cdot \mathrm{L}^{-1}$ confirming what was observed in the PDP results (Figure $1(\mathrm{c})$ ). A decrease in $C_{\mathrm{dl}}$-values was also observed by Felhósi et al. [48], indicating formation of protective film on the metal surface. Film stabilization is supported by a more capacitive behavior due to an increase in the value of $n$ reaching the value of $0.880(0.1[\mathrm{~V} v s . \mathrm{SCE}])$. In the same potential ( 0.1 [ $\mathrm{V}$ vs. SCE]) but the presence of $20 \mathrm{mg} \cdot \mathrm{L}^{-1}$ of $\mathrm{Zn}^{2+}$, a higher $R_{\mathrm{p}}$ value was obtained showing that a protective film consisting of $\mathrm{Zn}(\mathrm{OH})_{2}$ occurred on the metal/solution interface making to harder pit development [49]. Through analyzing the parameters obtained in the three distinct potentials under study, possible adsorption of $\mathrm{Mg}(\mathrm{OH})_{2}$ in the cathodic region is observed due to a slight lowering of $C_{\mathrm{dl}}$. The characteristic of $\mathrm{Mg}$ to promote the stabilization of the pro- 
tective film is confirmed by decrease in $C_{\mathrm{dl}}$-values and an increase of parameter $n$ for the addition of $10 \mathrm{mg} \cdot \mathrm{L}^{-1}$ at 0.1 [V vs. SCE]. This fact is linked to the substitution of molecules of water adsorbed on the metal surface by inhibitory molecules, suggesting an increasing thickness of the electrical double layer and reducing the active area of the AISI 304 stainless steel [50] [51].

\subsection{SEM after Potential Measurements}

Figure 6 shows the influence of the addition of $\mathrm{Ca}, \mathrm{Zn}$, and $\mathrm{Mg}$ elements in a solution containing $50 \mathrm{mg} \cdot \mathrm{L}^{-1} \mathrm{HEDP}$ on the AISI 304 stainless steel surface after open circuit potential measurements. It is observed that in the absence of divalent cations, the deposition of $\mathrm{NaCl}$ crystals on the metal surface was verified and the corrosion product is justified by the presence of $\mathrm{Fe}$ and $\mathrm{Cl}$ in the EDS spectra (Figure S5 in the supplementary material) and the elemental mapping (Figure $\mathrm{S} 6$ in the supplementary material). $\mathrm{Fe}^{2+}$ ions from the oxidation reaction (Equation 12) reacts with chloride ions $\left(\mathrm{Cl}^{-}\right)$present in the medium and forms $\mathrm{FeCl}_{2(\mathrm{~s})}$ as shown in equation 13. The formation of this solid in aqueous solution
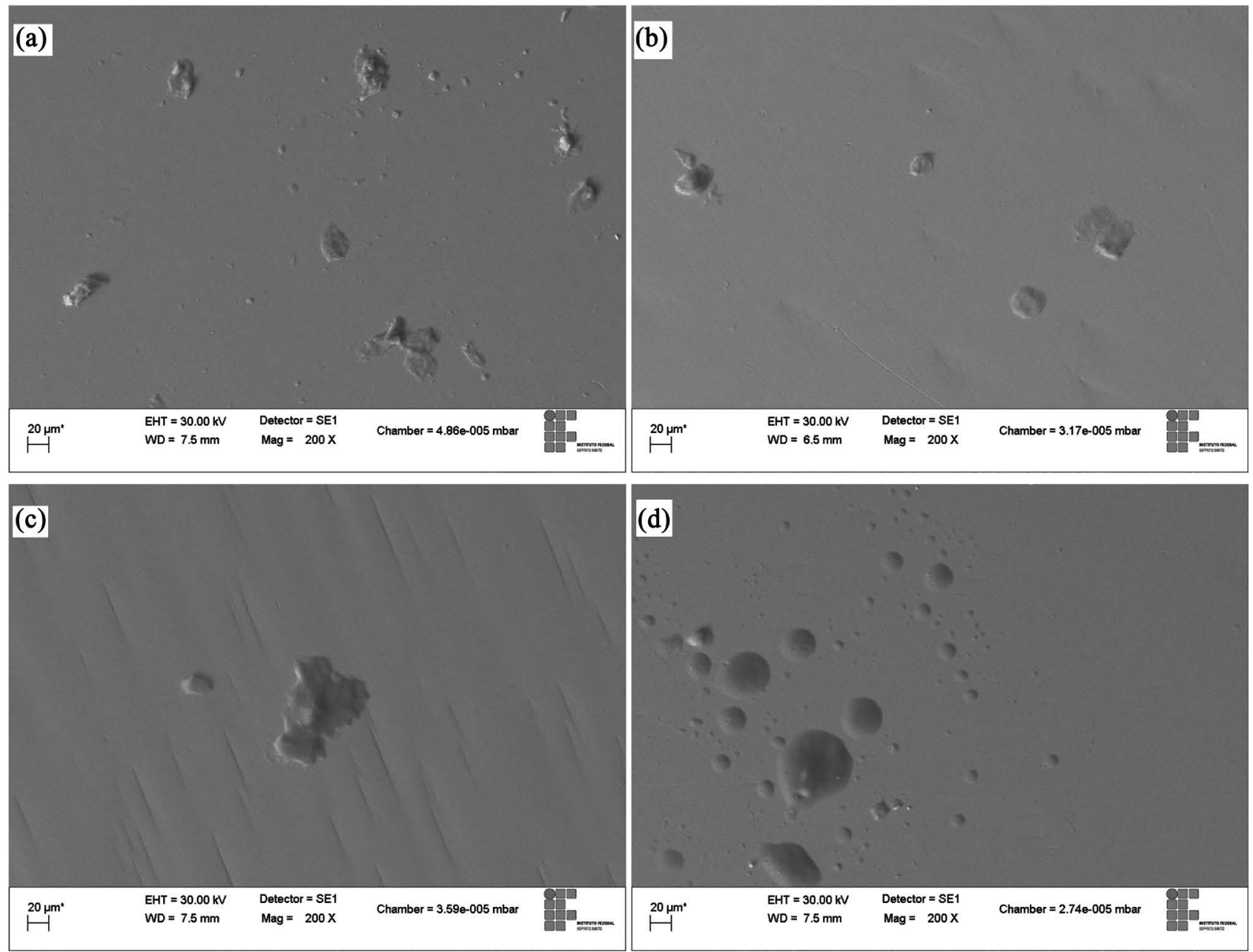

Figure 6. SEM images for AISI 304 stainless steel, after an open circuit potential scan. (a) $50 \mathrm{mg} \cdot \mathrm{L}^{-1} \mathrm{HEDP}$; (b) $50 \mathrm{mg} \cdot \mathrm{L}^{-1} \mathrm{HEDP}+$ $10 \mathrm{mg} \cdot \mathrm{L}^{-1} \mathrm{Ca}^{2+}$; (c) $50 \mathrm{mg} \cdot \mathrm{L}^{-1} \mathrm{HEDP}+10 \mathrm{mg} \cdot \mathrm{L}^{-1} \mathrm{Zn}^{2+}$; (d) $50 \mathrm{mg} \cdot \mathrm{L}^{-1} \mathrm{HEDP}+10 \mathrm{mg} \cdot \mathrm{L}^{-1} \mathrm{Mg}^{2+}$; Magnification: $200 \times$. 
favors the reduction of the solution's $\mathrm{pH}$ providing acceleration of the corrosive process [52]. The product formed around the pit is composed of $\mathrm{Fe}(\mathrm{OH})_{2}$ (Equation (14)) and the product formed inside the pit is composed of $\mathrm{FeCl}_{2}$ [53]. However, the inhibitor adsorption is observed on the metal surface due to the presence of Fe and C (Figure S5 and Figure S6 in the supplementary material) [54], indicating that possibly there was a decrease in the rate of oxygen reduction and/or iron dissolution reactions.

$$
\begin{gathered}
\mathrm{Fe}(\mathrm{s}) \rightleftarrows \mathrm{Fe}^{2+}(\mathrm{aq})+2 \mathrm{e}^{-} \\
\mathrm{Fe}^{2+}(\mathrm{aq})+2 \mathrm{Cl}^{-}(\mathrm{aq}) \rightleftarrows \mathrm{FeCl}_{2}(\mathrm{~s}) \\
\mathrm{FeCl}_{2}(\mathrm{~s})+2 \mathrm{H}_{2} \mathrm{O}(\mathrm{l}) \rightleftarrows \mathrm{Fe}(\mathrm{OH})_{2}(\mathrm{~s})+2 \mathrm{H}^{+}(\mathrm{aq})+2 \mathrm{Cl}^{-}(\mathrm{aq})
\end{gathered}
$$

EDS analysis of the samples immersed in a solution containing the divalent cations showed that the presence of $\mathrm{Cl}^{-}$species was not verified, suggesting that the inhibitor favored a barrier for chloride ion penetrations (Figure S6(b), Figure S7(b), and Figure S8(b) in the supplementary material). The non-stabilizing characteristic of the protective film, guaranteed by the presence of $\mathrm{Ca}^{2+}$ cations, is justified by a lower intensity signal from $\mathrm{C}$ in the EDS spectra (Figure S6(a) in the supplementary material). For the presence of $\mathrm{Zn}^{2+}$, a signal from $\mathrm{C}$ similar to the presence of $50 \mathrm{mg} \cdot \mathrm{L}^{-1} \mathrm{HEDP}$ was found (Figure S7(a) in the supplementary material). A higher inhibitory behavior on film stabilization with the presence of $\mathrm{Mg}^{2+}$ is supported by the presence of a higher intensity signal from C (Figure S8(a) in the supplementary material), suggesting the formation of a more homogeneous barrier with greater protective features against corrosive attacks.

\subsection{Weight Loss Measurements}

Table 2 shows the corrosion rate $\left(C_{\mathrm{R}}\right)$, surface coverage, and inhibitor efficiency $\left(\eta_{m}\right)$. From the results obtained it is clear that the efficiency of the inhibitor is increased with the addition of divalent cations, corroborated with the results obtained by electrochemical tests (PDP and EIS data). The presence of $\mathrm{Zn}^{2+}$ favored a maximum efficiency $\left(\eta_{\mathrm{m}}=85.2 \%\right)$ followed by $\mathrm{Mg}^{2+}\left(\eta_{\mathrm{m}}=70.4 \%\right)$. This result is in agreement with that observed in the EIS test, where at the $E_{\text {corr }}$ in the presence of $\mathrm{Zn}^{2+}$ culminated in higher resistance to the corrosive process. A higher weight loss value obtained by the addition of $\mathrm{Ca}^{2+}$ implies that this cation is not responsible for the stabilization of the protective film. Comparing the

Table 2. Results obtained in the weight loss test.

\begin{tabular}{cccc}
\hline Concentration $\left(\mathrm{mg} \cdot \mathrm{L}^{-1}\right)$ & $C_{\mathrm{R}}\left(\mathrm{mm} \mathrm{year}{ }^{-1}\right)$ & Surface coverage $(\theta)$ & $\eta_{\mathrm{m}}(\%)$ \\
\hline 0 & $2.74 \times 10^{-2}$ & -- & -- \\
$50 \mathrm{HEDP}$ & $1.98 \times 10^{-2}$ & 0.277 & 27.7 \\
$50 \mathrm{HEDP}+10 \mathrm{Ca}^{2+}$ & $1.16 \times 10^{-2}$ & 0.577 & 57.7 \\
$50 \mathrm{HEDP}+10 \mathrm{Zn}^{2+}$ & $4.05 \times 10^{-3}$ & 0.852 & 85.2 \\
$50 \mathrm{HEDP}+10 \mathrm{Mg}^{2+}$ & $8.11 \times 10^{-3}$ & 0.704 & 70.4 \\
\hline
\end{tabular}


efficiency values obtained in the EIS technique (Table 1) and by weight loss (Table 2) a significant difference in the values is observed. Lower values found in the EIS-results may be related to the presence of iron oxide on the metal surface, which it could not observe in the weight loss because the samples were subjected to pickling treatment.

\section{Conclusions}

The potentiodynamic polarization studies indicated that HEDP is an inhibitor anodic type. EIS-results showed an increase in $R_{\mathrm{p}}$-values and a decrease in $C_{\mathrm{dl}}$-values, indicating adsorption of the molecule on the material surface.

The addition of calcium ions favored a cathodic behavior of the inhibitor. At the potential -0.3 [V vs. SCE], the concentration of $10 \mathrm{mg} \cdot \mathrm{L}^{-1} \mathrm{Ca}^{2+}+50 \mathrm{mg} \cdot \mathrm{L}^{-1}$ HEDP provided a higher $R_{\mathrm{p}}$-value, increasing the inhibitor efficiency. However, at the potential 0.1 [ $\mathrm{V}$ vs. SCE], when one increased cation concentrations, a larger deformed semicircle was observed suggesting that this element facilitates adsorption but does not stabilize the protective film.

At the corrosion potential and 0.1 [ $\mathrm{V} v s$. SCE] the addition of $\mathrm{Zn}$ was positive, especially for the concentration of $20 \mathrm{mg} \cdot \mathrm{L}^{-1}$. This fact indicates that the HEDP inhibitor not only favors better adsorption but also stabilizes the $\mathrm{Zn}(\mathrm{OH})_{2}$ film formed on the cathodic sites. The addition of magnesium had a similar effect to the addition of zinc in the corrosive medium, suggesting the formation of $\mathrm{Mg}(\mathrm{OH})_{2}$ on the cathodic sites.

SEM and EDS analyses corroborated with PDP and EIS results because these investigations showed that the addition of $\mathrm{Zn}^{2+}$ and $\mathrm{Mg}^{2+}$ ions favored greater inhibitor effectiveness by blocking the effect of chloride and sulfide ions on the corrosion process (inhibitor efficiency, for $\mathrm{Zn}^{2+} \eta_{\mathrm{m}}=85.2 \%$ and for $\mathrm{Mg}^{2+} \eta_{\mathrm{m}}=$ $70.4 \%)$. The weight loss results corroborated with the electrochemical results showing that the presence of $\mathrm{Zn}^{2+}$ and $\mathrm{Mg}^{2+}$ cations favored a lower weight loss on AISI 304 stainless steel.

For a better understanding corrosion process using HEDP inhibitor, we suggest making an appropriate study for each of the chloride and sulfide ions separately. In addition, studies by scanning electrochemical microscopy can be carried out to analyze as to the adsorption of the inhibitor along with the divalent cations.

\section{Acknowledgements}

The authors gratefully acknowledge Conselho Nacional de Desenvolvimento Científico e Tecnológico (CNPq), Coordenação de Aperfeiçoamento de Pessoal de Nível Superior (CAPES), and Fundação de Amparo à Pesquisa e Inovação do Espirito Santo (FAPES) for providing financial support, and Drs. Gontijo, L. C. and Boldrini, R. for their support in SEM and EDS analysis and Dr. Eliane D'Elia for support in the PDP and EIS discussion. The authors also acknowledge the Tribology, Corrosion, and Materials Laboratory (TRICORRMAT) at the 
Mechanical Engineering Department of the Federal University of Espírito Santo by the optical microscopy analyses.

\section{Conflicts of Interest}

The authors declare no conflicts of interest regarding the publication of this paper.

\section{References}

[1] Li, Y.Z., Wang, X. and Zhang, G.A. (2019) Corrosion Behaviour of 13Cr Stainless Steel under Stress and Crevice in 3.5 wt.\% NaCl Solution. Corrosion Science, 163, Article ID: 108290. https://doi.org/10.1016/j.corsci.2018.12.018

[2] Xu, X., Liu, S., Liu, Y., Smith, K. and Cui, Y. (2019) Corrosion of Stainless Steel Valves in a Reverse Osmosis System: Analysis of Corrosion Products and Metal Loss. Engineering Failure Analysis, 105, 40-51. https://doi.org/10.1016/j.engfailanal.2019.06.026

[3] Cui, Y., Liu, S., Smith, K., Yu, K., Hu, H. and Jiang, W. (2016) Characterization of Corrosion Scale Formed on Stainless Steel Delivery Pipe for Reclaimed Water Treatment. Water Research, 88, 816-825. https://doi.org/10.1016/j.watres.2015.11.021

[4] Uhlig, H.H. and Revie, R.W. (2008) Corrosion and Corrosion Control. 2nd Edition, John Wiley \& Sons Inc., Hoboken, 513.

[5] Loto, R.T., Loto, C.A., Popoola, A.P.I. and Fedotova, T. (2015) Inhibition Effect of Butan-1-Ol on the Corrosion Behavior of Austenitic Stainless Steel (Type 304) in Dilute Sulfuric Acid. Arabian Journal of Chemistry, 12, 2270-2279. https://doi.org/10.1016/j.arabjc.2014.12.024

[6] Wang, X., Yang, Z., Wang, Z., Shi, Q., Xu, B. and Zhou, C. (2019) The Influence of Copper on the Stress Corrosion Cracking of 304 Stainless Steel. Applied Surface Science, 478, 492-498. https://doi.org/10.1016/j.apsusc.2019.01.291

[7] Zhang, G.A., Hou, X.M., Hou, B.S. and Liu, H.F. (2019) Benzimidazole Derivatives as Novel Inhibitors for the Corrosion of Mild Steel in Acidic Solution: Experimental and Theoretical Studies. Journal of Molecular Liquids, 278, 413-427. https://doi.org/10.1016/j.molliq.2019.01.060

[8] Naveen, E., Ramnath, B.V., Elanchezhian, C. and Mohamed, N.S.S. (2017) Influence of Organic Corrosion Inhibitors on Pickling Corrosion Behaviour of Sinter-Forged C45 Steel and 2\% Cu Alloyed C45 Steel. Journal of Alloys and Compounds, 695, 3299-3309. https://doi.org/10.1016/j.jallcom.2016.11.133

[9] Qiang, Y., Zhang, S., Tan, B. and Chen, S. (2018) Evaluation of Ginkgo Leaf Extract as an Eco-Friendly Corrosion Inhibitor of X70 Steel in $\mathrm{HCl}$ Solution. Corrosion Science, 133, 6-16. https://doi.org/10.1016/j.corsci.2018.01.008

[10] Rosliza, R., Wan, N.W.B., Izman, S. and Prawoto, Y. (2010) Anti-Corrosive Properties of Natural Honey on Al-Mg-Si Alloy in Seawater. Current Applied Physics, 10, 923-929. https://doi.org/10.1016/j.cap.2009.11.074

[11] Goyal, M., Kumar, S., Behadur, I., Verma, C. and Ebenso, E.E. (2018) Organic Corrosion Inhibitors for Industrial Cleaning of Ferrous and Non-Ferrous Metals in Acidic Solutions: A Review. Journal of Molecular Liquids, 256, 565-573. https://doi.org/10.1016/j.molliq.2018.02.045

[12] Awad, H.S. (2005) The Effect of Zinc-to-HEDP Molar Ratio on the Effectiveness of Zinc-1, Hydroxyethylidene-1,1 Diphosphonic Acid in Inhibiting Corrosion of 
Carbon Steel in Neutral Solutions. Anti-Corrosion on Methods and Materials, 52, 22-28. https://doi.org/10.1108/00035590510574880

[13] Zheng, J., Chen, H., Cai, W., Qiao, L., Ying, Y., Li, W., Yu, J. and Jiang, L. (2017) Reaction Mechanisms of Copper Electrodeposition from 1-Hydroxyethylidene-1,1Diphosphonic Acid (HEDP) Solution on Glassy Carbon. Materials Science and Engineering B, 224, 18-27. https://doi.org/10.1016/j.mseb.2017.07.004

[14] Hoffmann, T., Friedel, P., Harnisch, C., Haußler, L. and Pospiech, D. (2012) Investigation of Thermal Decomposition of Phosphonic Acids. Journal of Analytical and Applied Pyrolysis, 96, 43-53. https://doi.org/10.1016/j.jaap.2012.03.001

[15] Yan, R., Gao, X., He, W., Chen, T. and Ma, H. (2019) 1-Hydroxyethylidene-1,1Diphosphonic Acid (HEDP)-Zn Complex Thin Films for the Corrosion Protection of Cold-Rolled Steel (CRS). Corrosion Science, 157, 116-125. https://doi.org/10.1016/j.corsci.2019.05.033

[16] Deluchat, V., Bollinger, J., Serpaud, B. and Caullet, C. (1997) Divalent Cations Speciation with Three Phosphonate Ligands in the $\mathrm{pH}$-Range of Natural Waters. Talanta, 44, 897-907. https://doi.org/10.1016/S0039-9140(96)02136-4

[17] Karmán, H., Felhosi, I., Kálmán, E., Cserny, I. and Kovér, L. (1998) The Role of Oxide Layer Formation during Corrosion Inhibition of Mild Steel in Neutral Aqueous Media. Electrochimica Acta, 43, 69-75. https://doi.org/10.1016/S0013-4686(97)00236-3

[18] Sekine, I. and Hirakawa, Y. (1986) Effect of 1-Hydroxyethylidene-1,1-Diphosphonic Acid on the Corrosion of SS 41 Steel in $0.3 \%$ Sodium Chloride Solution. Corrosion, 42, 272-277. https://doi.org/10.5006/1.3584904

[19] Sekine, I., Shimode, T., Yuasa, M., Takaoka, K. and Takaoka, K. (1990) Corrosion Inhibition of Structural Steels in the $\mathrm{CO}_{2}$ Absorption Process by 1-(Hydroxyethylidene)1,1-diphosphonic Acid. Industrial and Engineering Chemistry Research, 29, 1460-1466. https://doi.org/10.1021/ie00103a054

[20] Awad, H.S. and Turgoose, S. (2002) Role of Complexes in Inhibition of Mild Steel by Zinc-1-hydroxyethylidene-1,1-diphosphonic Acid Mixtures. British Corrosion Journal, 37, 147-154. https://doi.org/10.1179/000705902225004347

[21] Mohammedi, D., Benmoussa, A., Fiaud, C. and Sutter, E.M.M. (2004) Synergistic or Additive Corrosion Inhibition of Mild Steel by a Mixture of HEDP and Metasilicate at $\mathrm{pH} 7$ and 11. Materials and Corrosion, 55, 837-844. https://doi.org/10.1002/maco.200403794

[22] Youssef, N., Elshahed, M.S. and McInerney, M.J. (2009) Microbial Processes in Oil Fields: Culprits, Problems, and Opportunities. Advances in Applied Microbiology, 66, 141-251. https://doi.org/10.1016/S0065-2164(08)00806-X

[23] Gieg, L.M., Jack, T.R. and Foght, J.M. (2011) Biological Souring and Mitigation in Oil Reservoirs. Applied Microbiology and Biotechnology, 92, 263-282. https://doi.org/10.1007/s00253-011-3542-6

[24] Fakhru'l-Razi, A., Pendashteh, A., Abdullah, L.C., Biak, D.R., Madaeni, S.S. and Abidin, Z.Z. (2009) Review of Technologies for Oil and Gas Produced Water Treatment. Journal of Hazardous Materials, 170, 530-551. https://doi.org/10.1016/j.jhazmat.2009.05.044

[25] Tibbetts, P.J.C., Buchanan, I.T., Gawel, L.J. and Large, R. (1992) A Comprehensive Determination of Produced Water Composition. In: Ray, J.P. and Engelhardt, F.R., Eds., Produced Water. TechnologicallEnvironmental Issues and Solutions, Plenum Publishing Corp., New York, 97-113. https://doi.org/10.1007/978-1-4615-2902-6_9 
[26] Hansen, B.R. and Davies, S.R. (1994) Review of Potential Technologies for the Removal of Dissolved Components from Produced Water. Chemical Engineering Research \& Design, 72, 176-188.

[27] ASTM A262-15 (2014) Standard Practices for Detecting Susceptibility to Intergranular Attack in Austenitic Stainless Steels.

[28] EIS Spectrum Analyser. http://www.abc.chemistry.bsu.by/vi/analyser

[29] Miao, M., Wang, J. and Hu, W. (2018) Synthesis, Characterization and Inhibition Properties of ZnAlCe Layered Double Hydroxide Intercalated with 1-Hydroxyethylidene-1,1-diphosphonic Acid. Colloids and Surfaces A: Physicochemical and Engineering Aspects, 543, 144-154. https://doi.org/10.1016/j.colsurfa.2018.01.056

[30] ASTM G31-72 (2004) Standard Practive for Laboratory Immersion Corrosion Testing of Metals. American Society for Testing and Materials, West Conshohocken.

[31] ASTM A308/1380M-17 (2017) Standard Practive for Cleaning, Descaling, and Passivation of Stainless Steel Parts, Equipment, and Systems. American Society for Testing and Materials, West Conshohocken.

[32] Qian, S. and Cheng, Y.F. (2019) Synergism of Imidazoline and Sodium Dodecylbenzenesulphonate Inhibitors on Corrosion Inhibition of X52 Carbon Steel in $\mathrm{CO}_{2}$-Saturated Chloride Solutions. Journal of Molecular Liquids, 294, Article ID: 111674. https://doi.org/10.1016/j.molliq.2019.111674

[33] ASM International, Handbook Commitee (2004) Metallography and Microstructure Prepared under the Direction on the ASM Handbook Committee. 9th Edition, Materials Park, 232-234. https://doi.org/10.1149/06120.0025ecst

[34] Soares, T.F., Moreira, R.R., de Andrade, A.R. and Ribeiro, J. (2014) Corrosion Studies of Austenitic and Ferritic Stainless Steels in Solution Containing Chloride Ions. ECS Transactions, 61, 25-36.

[35] Pradhan, S.K., Bruyan, P. and Mandal, S. (2019) Influence of the Individual Microstructural Features on Pitting Corrosion in Type 304 Austenitic Stainless Steel. Corrosion Science, 158, Article ID: 108091. https://doi.org/10.1016/j.corsci.2019.108091

[36] Salasi, M., Shahrabi, T. and Roayaei, E. (2007) Effect of Inhibitor Concentration and Hydrodynamic Conditions on the Inhibitive Behaviour of Combinations of Sodium Silicate and HEDP for Corrosion Control in Carbon Steel Water Transmission Pipes. Anti-Corrosion Methods and Materials, 54, 82-92. https://doi.org/10.1108/00035590710733575

[37] Verma, C., Sorour, A.A., Ebenso, E.E. and Quaraishi, M.A. (2018) Inhibition Performance of Three Naphthyridine Derivatives for Mild Steel Corrosion in 1M HCl: Computation and Experimental Analyses. Results in Physics, 10, 504-511. https://doi.org/10.1016/j.rinp.2018.06.054

[38] EL-Raouf, M.A., Khamis, E.A., Maran, T.H., Kana, A. and Nabel, A.N. (2018) Electrochemical and Quantum Chemical Evaluation of New Bis(coumarins) Derivatives as Corrosion Inhibitors for Carbon Steel Corrosion in $0.5 \mathrm{M} \mathrm{H}_{2} \mathrm{SO}_{4}$. Journal of Molecular Liquids, 255, 341-353. https://doi.org/10.1016/j.molliq.2018.01.148

[39] Aoun, S.B., Bouklah, M., Khaled, K.F. and Hammouti, B. (2016) Electrochemical Impedance Spectroscopy Investigations of Steel Corrosion in Acid Media in the Presence of Thiophene Derivatives. International Journal of Electrochemical Science, 11, 7343-7358. https://doi.org/10.20964/2016.09.07

[40] Zenobi, M.C., Luengo, C.V., Avena, M.J. and Rueda, E.H. (2008) An ATR-FTIR Study of Different Phosphonic Acids in Aqueous Solution. Spectrochimica Acta. 
Part A, Molecular and Biomolecular Spectroscopy, 70, 270-276. https://doi.org/10.1016/j.saa.2007.07.043

[41] Reznik, L.Y., Sathler, L., Cardoso, M.J.B. and Albuquerque, M.G. (2008) Experimental and Theoretical Structural Analysis of Zn(II)-1-hydroxyethane-1,1-diphosphonic Acid Corrosion Inhibitor Films in Chloride Ions Solution. Materials and Corrosion, 59, 685-690. https://doi.org/10.1002/maco.200804108

[42] Moreira, R., Soares, T. and Ribeiro, J. (2014) Electrochemical Investigation of Corrosion on AISI 316 Stainless Steel and AISI 1010 Carbon Steel: Study of the Behaviour of Imidazole and Benzimidazole as Corrosion Inhibitors. Advances in Chemical Engineering and Science, 4, 503-514. https://doi.org/10.4236/aces.2014.44052

[43] Fu, J., Li, F., Sun, J., Cui, K., Du, X. and Wu, Y. (2019) Effect of Crystallographic Orientations on the Corrosion Resistance of Fe-17Cr Ferritic Stainless Steel. Journal of Electroanalytical Chemistry, 841, 56-62. https://doi.org/10.1016/j.jelechem.2019.04.031

[44] Verma, C., Singh, A., Pallikondo, G., Chakravarty, M. and Quraishi, M.A. (2015) Electrochemical, Thermodynamic, Surface and Theoretical Investigation of 2-Aminobenzene-1,3-dicarbonitriles as Green Corrosion Inhibitor for Aluminum in 0.5M NaOH. Journal of Molecular Liquids, 209, 767-778. https://doi.org/10.1016/j.molliq.2015.06.039

[45] Askari, M., Aliofkhazrali, M., Ghaffari, S. and Hajizadeh, A. (2018) Film Former Corrosion Inhibitors for Oil and Gas Pipelines-A Technical Review. Journal of Natural Gas Science and Engineering, 58, 92-114. https://doi.org/10.1016/j.jngse.2018.07.025

[46] Córdoba-Torres, P., Mesquita, T.J., Devos, O., Tribollet, B., Rocha, V. and Nogueira, R.P. (2012) Theory of the Frequency Dispersion of Electrode Polarization. Topology of Networks with Fractional Power Frequency Dependence. Electrochimica Acta, 72, 172-178. https://doi.org/10.1016/j.electacta.2012.04.020

[47] Zhang, H.H., Pang, X. and Gao, K. (2018) Localized $\mathrm{CO}_{2}$ Corrosion of Carbon Steel with Different Microstructures in Brine Solutions with an Imidazoline-Based Inhibitor. Applied Surface Science, 442, 446-460. https://doi.org/10.1016/j.apsusc.2018.02.115

[48] Felhõsi, I., Keresztes, Z., Kármán, F.H., Mohai, M., Bertóti, I. and Kálmán, E. (1999) Effects of Bivalent Cations on Corrosion Inhibition of Steel by 1-Hydroxyethane1,1-diphosphonic Acid. Journal of The Electrochemical Society, 146, 961-969. https://doi.org/10.1149/1.1391706

[49] Yan, D., Ye, Y., Su, Y., Liu, S., Gong, D. and Zhao, H. (2019) Corrosion Inhibition Behavior and Mechanism of N-Doped Carbon Dots for Metal in Acid Environment. Journal of Cleaner Production, 229, 180-192.

[50] Khan, G., Basirun, W.J., Kazi, S.N., Ahmed, P., Magaji, L., Ahmed, S.M., Khan, G.M., Rehman, M.A. and Badry, A. (2017) Electrochemical Investigation on the Corrosion Inhibition of Mild Steel by Quinazoline Schiff Base Compounds in Hydrochloric Acid Solution. Journal of Colloid and Interface Science, 502, 134-145. https://doi.org/10.1016/j.jcis.2017.04.061

[51] Fernandes, C.M., Fagundes, T.S.F., dos Santos, N.E., Rocha, T.S.M., Garrett, R., Borges, R.M., Muricy, G., Valverde, A.L. and Ponzio, E.A. (2019) Ircinia strobilina Crude Extract as Corrosion Inhibitor for Mild Steel in Acid Medium. Electrochimica Acta, 312, 137-148. https://doi.org/10.1016/j.electacta.2019.04.148

[52] Loto, R.T., Joseph, O.O. and Akanji, O. (2015) Electrochemical Corrosion 
Behaviour of Austenitic Stainless Steel (Type 304) in Dilute Hydrochloric Acid Solution. Journal of Material Environmental Science, 6, 2409-2417.

[53] Ma, Y.F. Corrosive Effects of Chlorides on Metals. http://cdn.intechopen.com/pdfs/33625/intechcorrosive_effects_of_chlorides_on_m etals.pdf

[54] Haddadi, A.S., Alibakhshi, E., Bahlakeh, G., Ramezanzadeh, B. and Mahdavian, M. (2019) A Detailed Atomic Level Computational and Electrochemical Exploration of the Juglans regia Green Fruit Shell Extract as a Sustainable and Highly Efficient Green Corrosion Inhibitor for Mild Steel in $3.5 \mathrm{wt} \% \mathrm{NaCl}$ Solution. Journal of Molecular Liquids, 284, 682-699. https://doi.org/10.1016/j.molliq.2019.04.045 


\section{Supplementary Material}<smiles>CC(O)(P(=O)(O)O)P(=O)(O)O</smiles>

Figure S1. Molecular structure of HEDP.

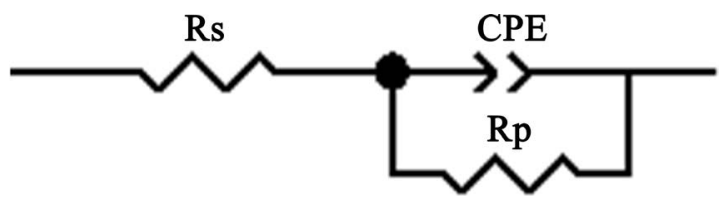

Figure S2. Equivalent electrical circuit for electrochemical impedance spectroscopy data simulation.

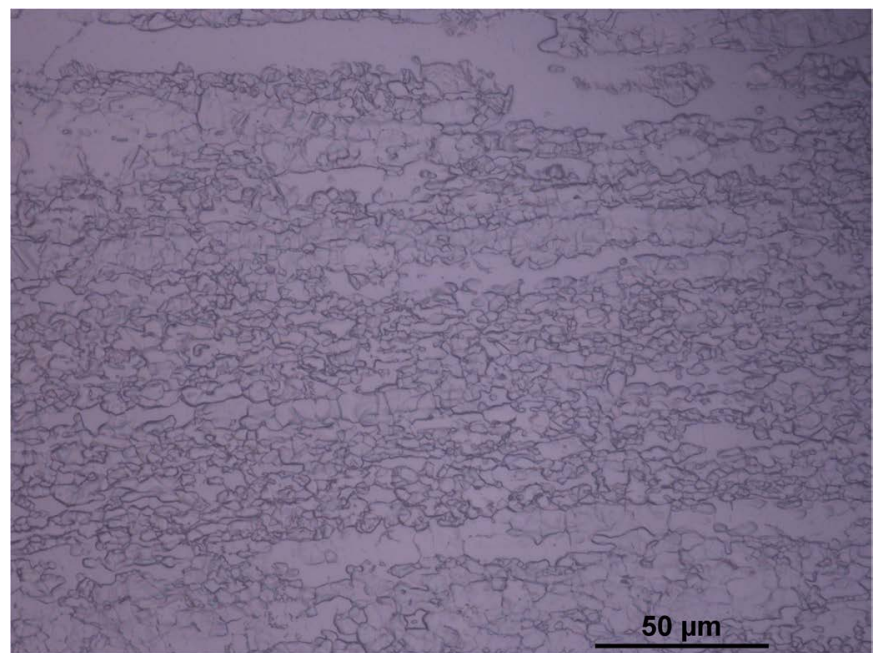

Figure S3. Micrograph of AISI 304 stainless steel before potentiodynamic polarization tests at 500x magnifications. Attack: Oxalic Acid 10 wt $\%$.
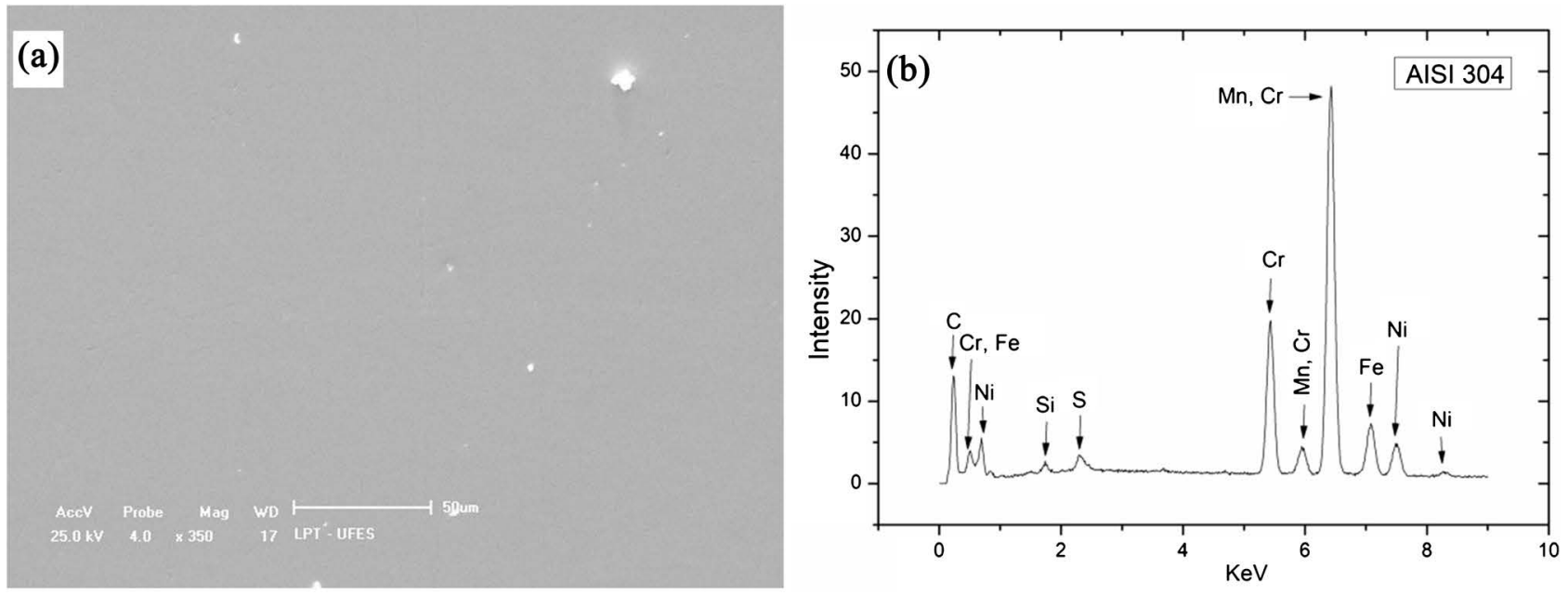

Figure S4. (a) SEM images and (b) EDS spectra for AISI 304 stainless steel, before applied potential. Magnification: 350×. 


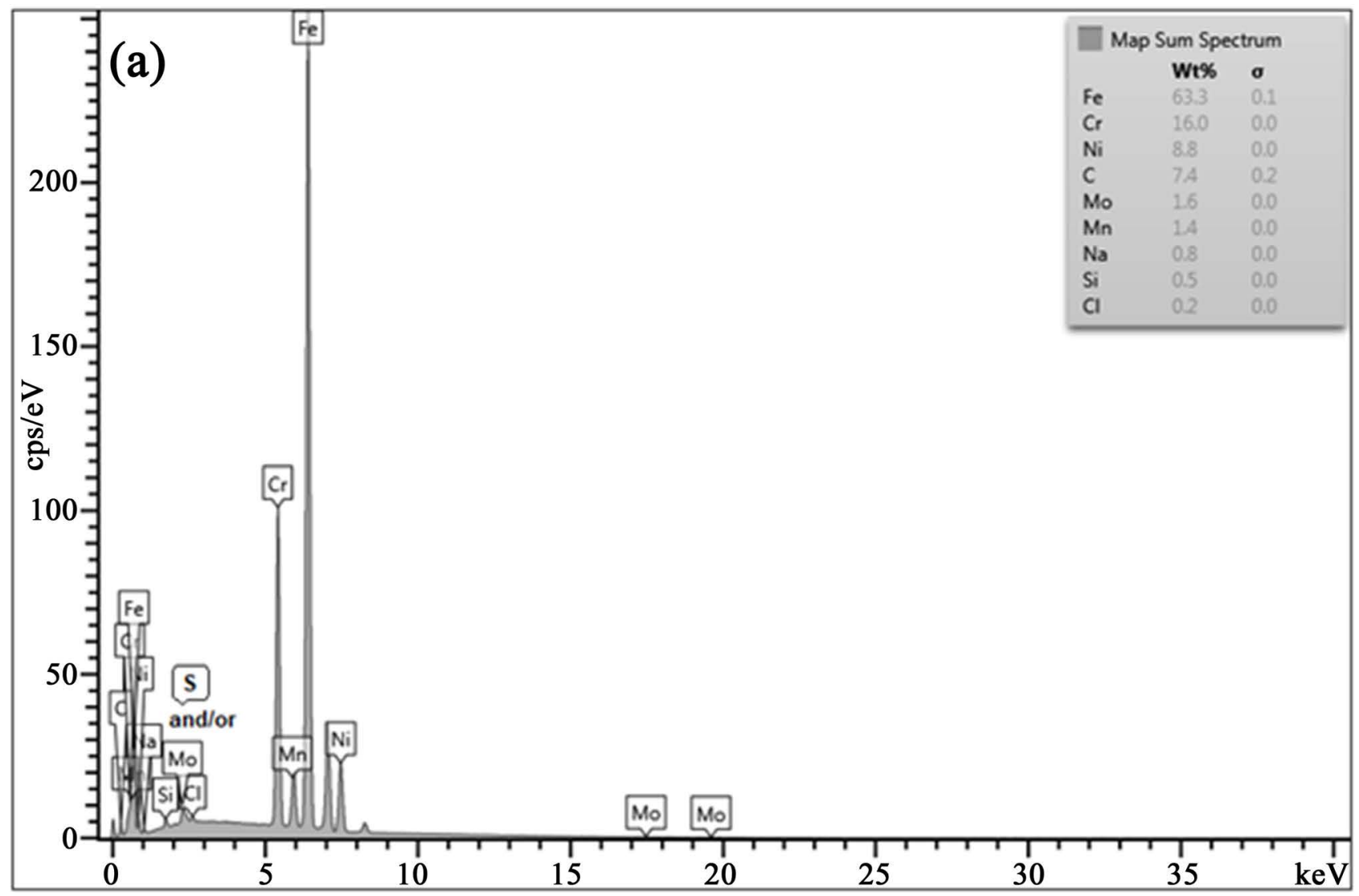

(b)
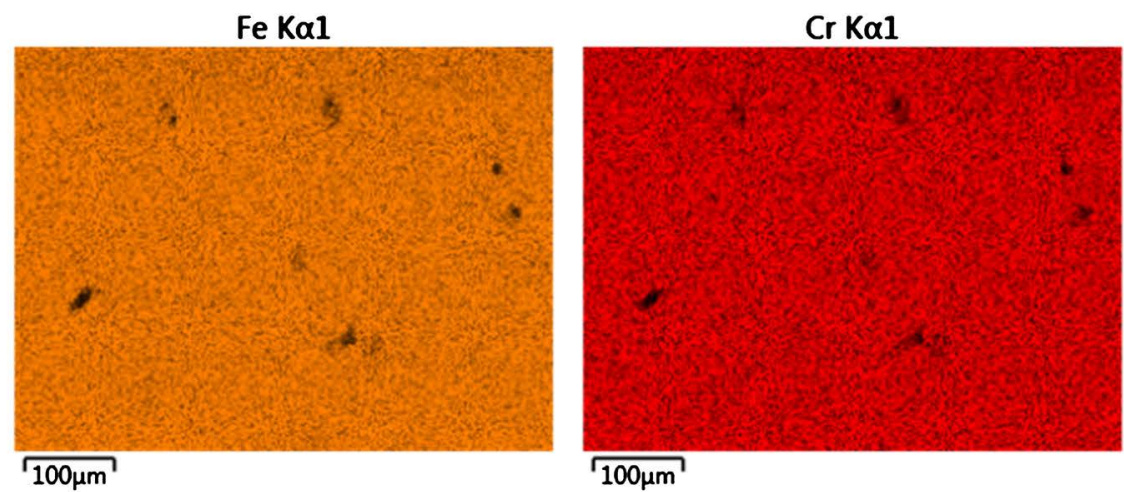

Ni Kal

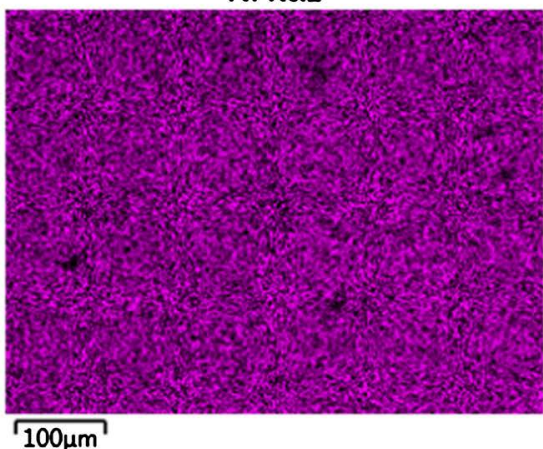

Mn Kal

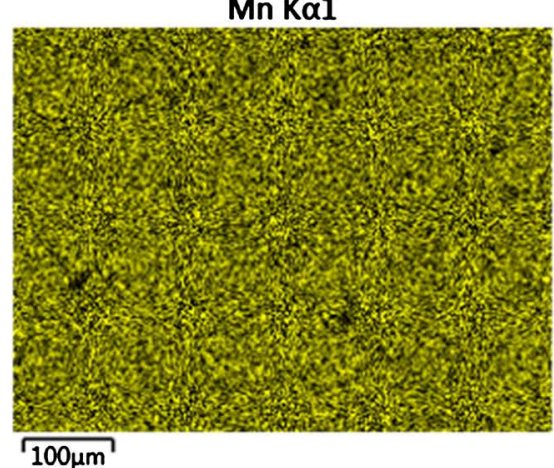



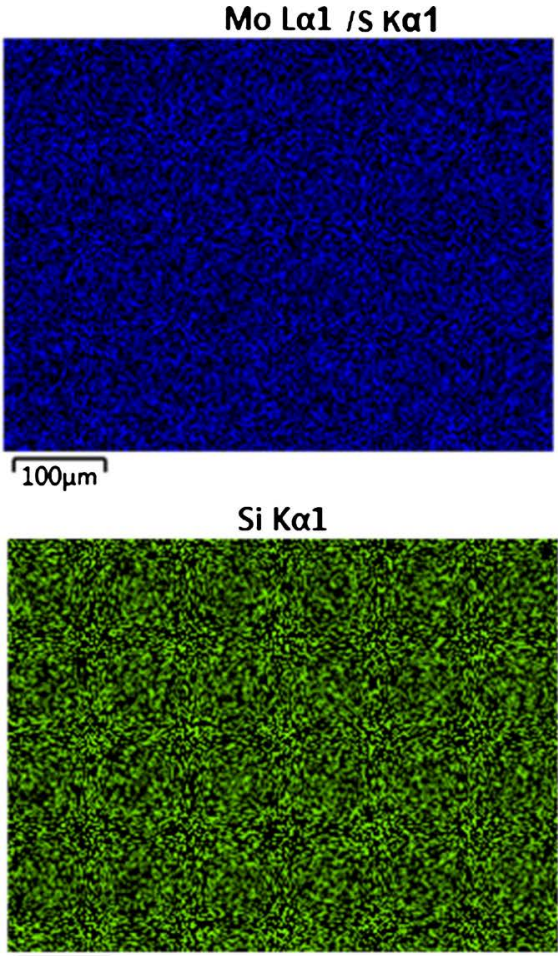

$\longdiv { 1 0 0 \mu \mathrm { m } }$

Na Ka1_2

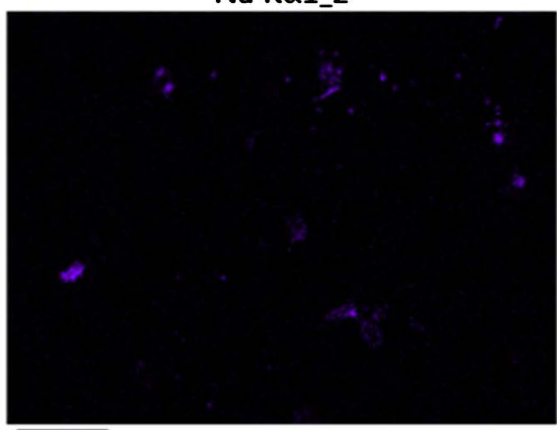

$\longdiv { 1 0 0 \mu \mathrm { m } }$

Figure S5. (a) EDS spectra and (b) Elemental mapping obtained for AISI 304 stainless steel, immersed in a solution containing $50 \mathrm{mg} \cdot \mathrm{L}^{-1} \mathrm{HEDP}, 3.5 \mathrm{wt} \% \mathrm{NaCl}$ and $1 \mathrm{mmol} \cdot \mathrm{L}^{-1}$ $\mathrm{Na}_{2} \mathrm{~S}$, after open circuit potential measurements. 


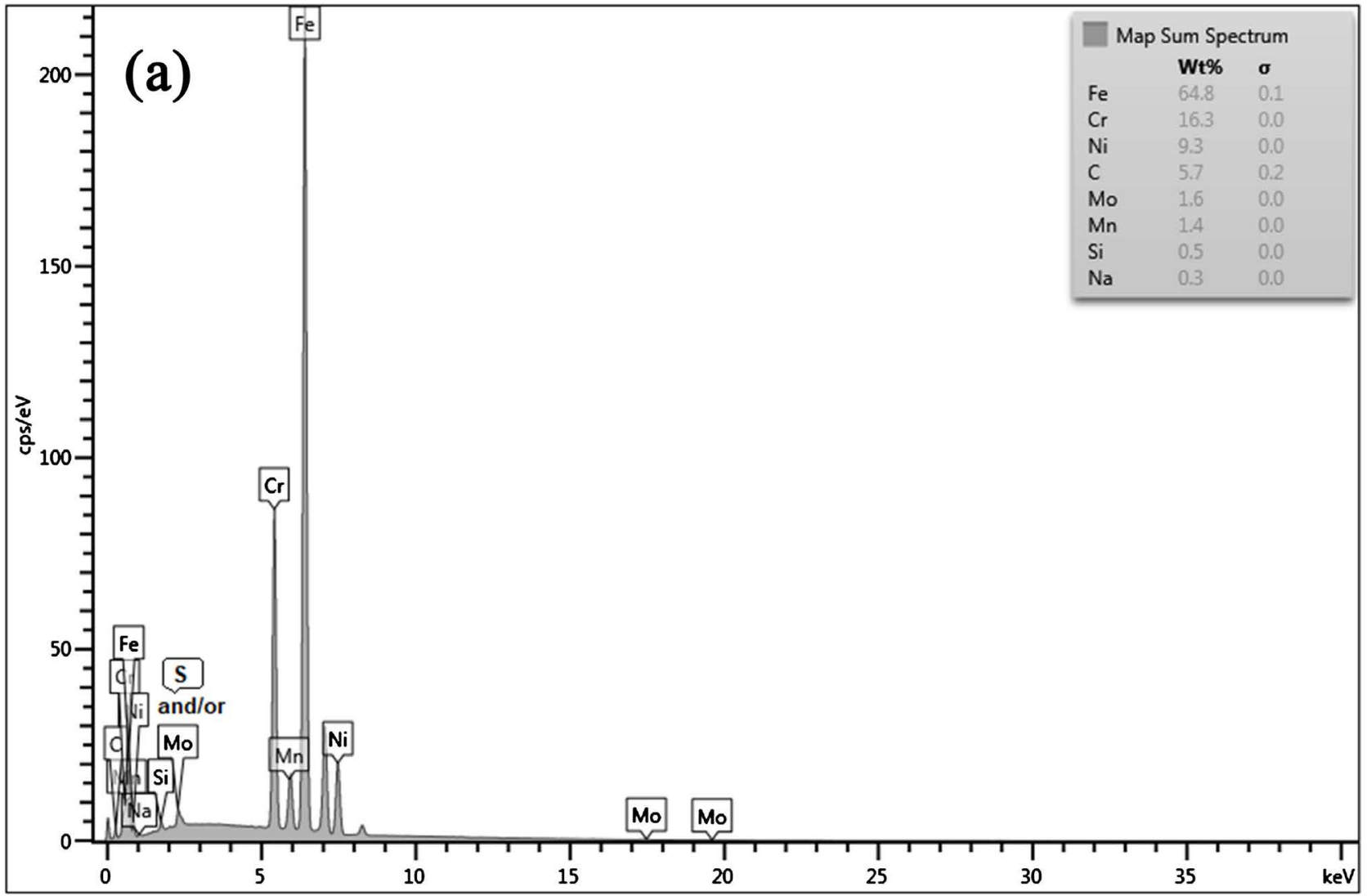

Fe K $\alpha 1$

(b)
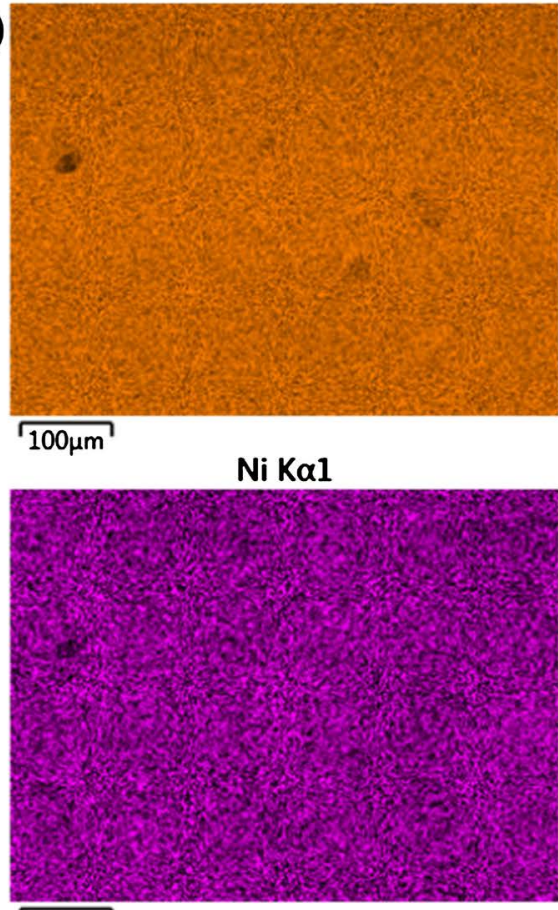

$\longdiv { 1 0 0 \mu \mathrm { m } }$
$\mathrm{Cr} K \alpha 1$

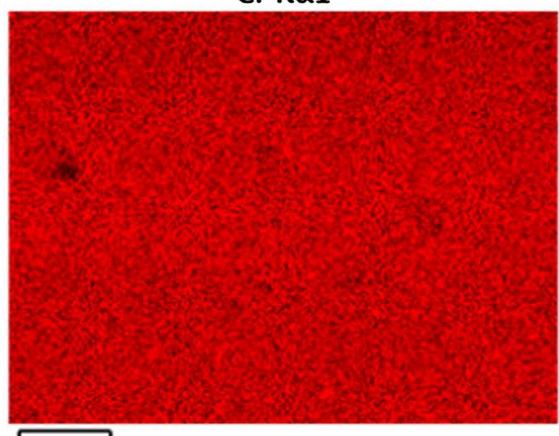

Mn Kal

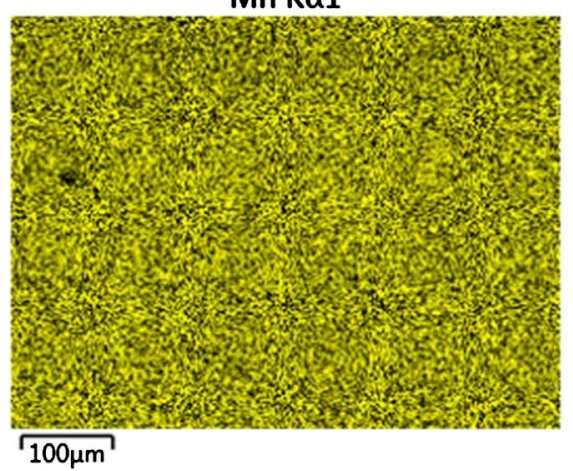




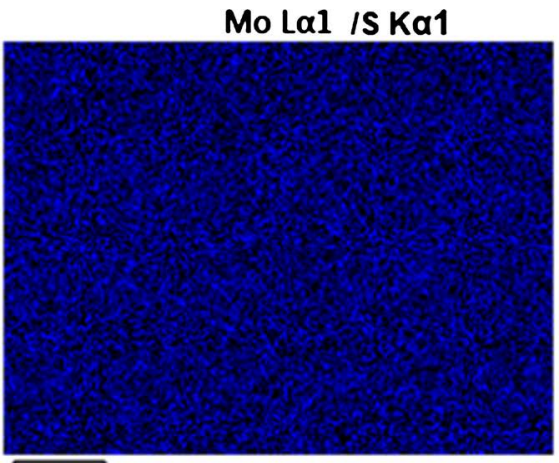

$\longdiv { 1 0 0 \mu \mathrm { m } }$

$\mathrm{CK \alpha 1} 2$

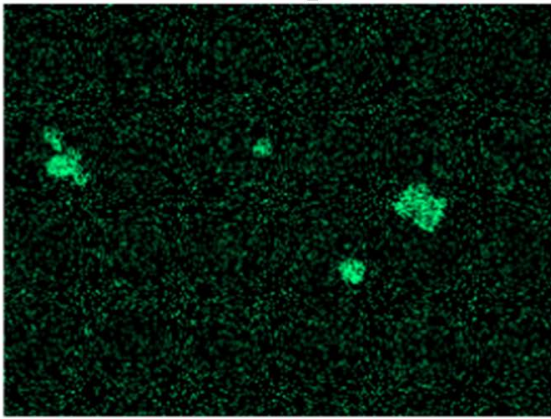

$\longdiv { 1 0 0 \mu \mathrm { m } }$

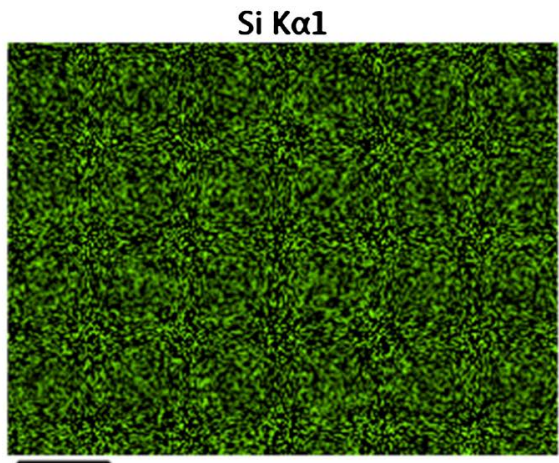

$\longdiv { 1 0 0 \mu \mathrm { m } }$

$\mathrm{NaK \alpha 1} 2$

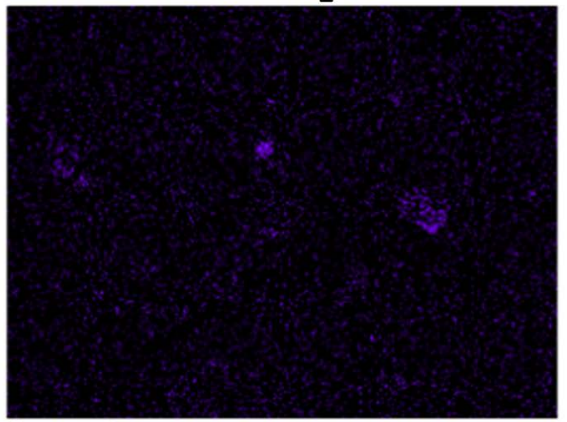

$\longdiv { 1 0 0 \mu \mathrm { m } }$

Figure S6. (a) EDS spectra and (b) Elemental mapping obtained for AISI 304 stainless steel, immersed in a solution containing $50 \mathrm{mg} \cdot \mathrm{L}^{-1} \mathrm{HEDP}, 3.5 \mathrm{wt} \% \mathrm{NaCl}, 1 \mathrm{mmol} \cdot \mathrm{L}^{-1}$ $\mathrm{Na}_{2} \mathrm{~S}$ and $10 \mathrm{mg} \cdot \mathrm{L}^{-1} \mathrm{CaCl}_{2}$ after open circuit potential measurements.

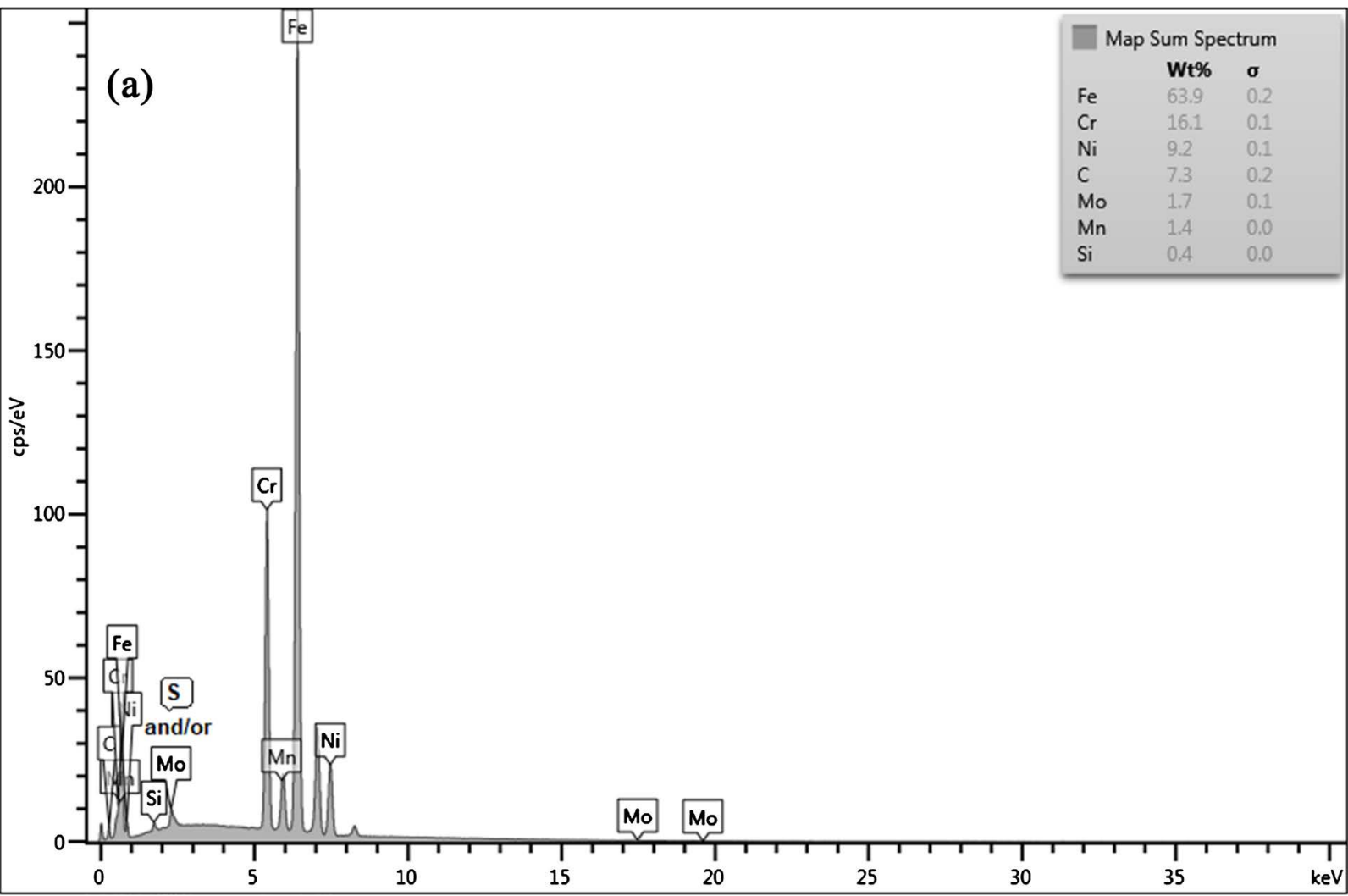


(b)

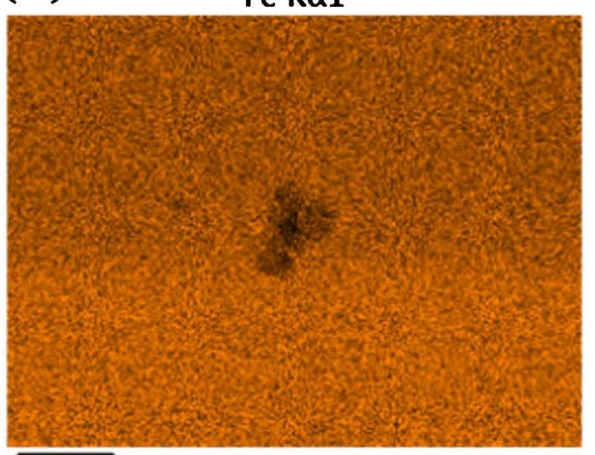

$\widehat{100 \mu \mathrm{m}}$

Ni Kal

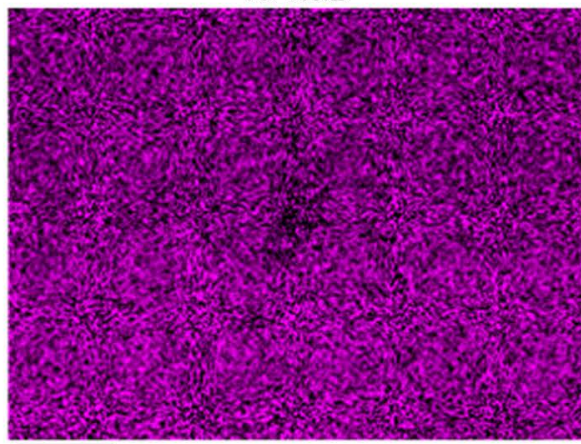

$100 \mu \mathrm{m}$

Mo La1 / S Ka1

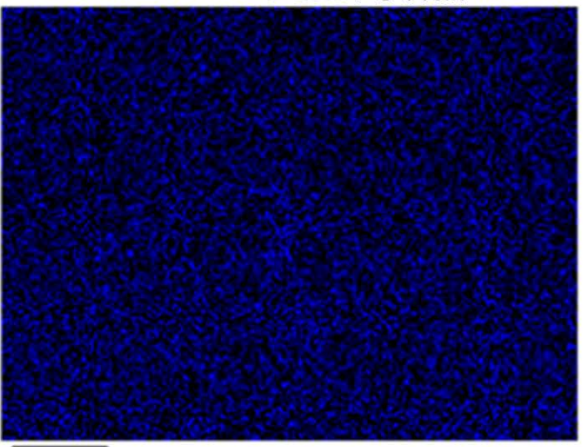

$\widehat{100 \mu \mathrm{m}}$

$C K \alpha 12$

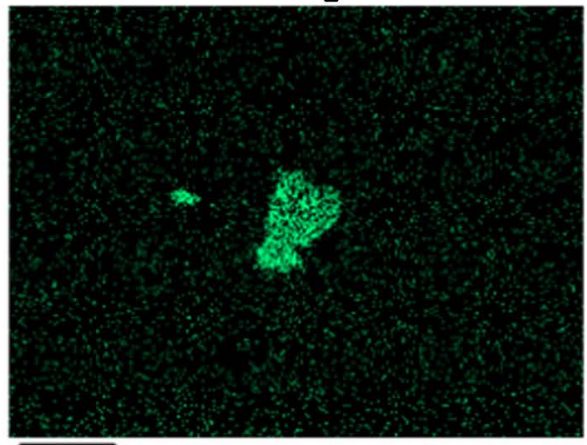

$\overparen{100 \mu \mathrm{m}}$
$\mathrm{Cr} \mathrm{K} \alpha \mathbf{l}$

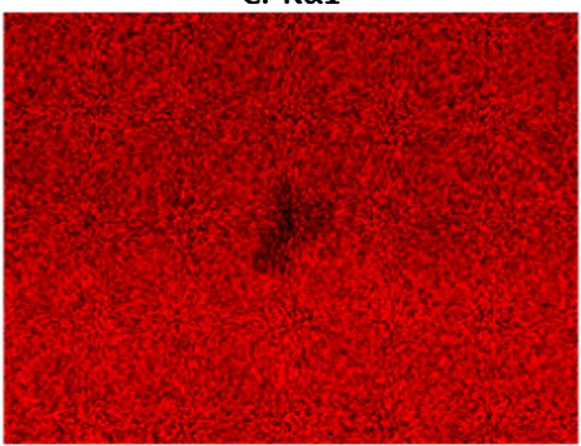

Mn Kal

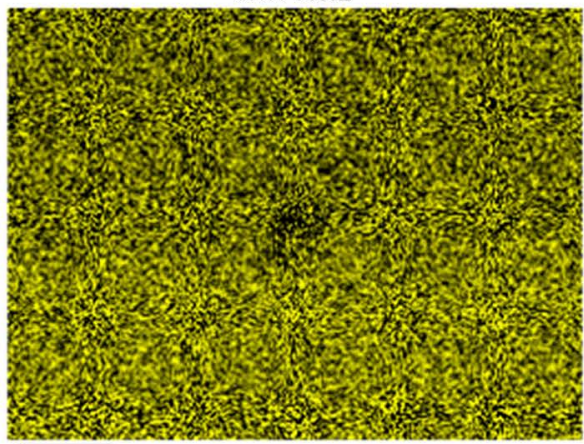

$\longdiv { 1 0 0 \mu \mathrm { m } }$

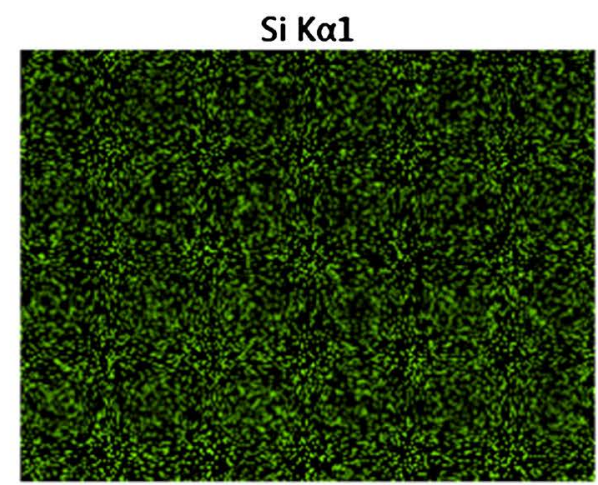

$\longdiv { 1 0 0 \mu m }$

Figure S7. (a) EDS spectra and (b) Elemental mapping obtained by EDS AISI 304 stainless steel, immersed in a solution containing $50 \mathrm{mg} \cdot \mathrm{L}^{-1} \mathrm{HEDP}, 3.5 \mathrm{wt} \% \mathrm{NaCl}, 1 \mathrm{mmol} \cdot \mathrm{L}^{-1} \mathrm{Na}_{2} \mathrm{~S}$ and $10 \mathrm{mg} \cdot \mathrm{L}^{-1} \mathrm{ZnCl}_{2}$, after open circuit potential measurements. 


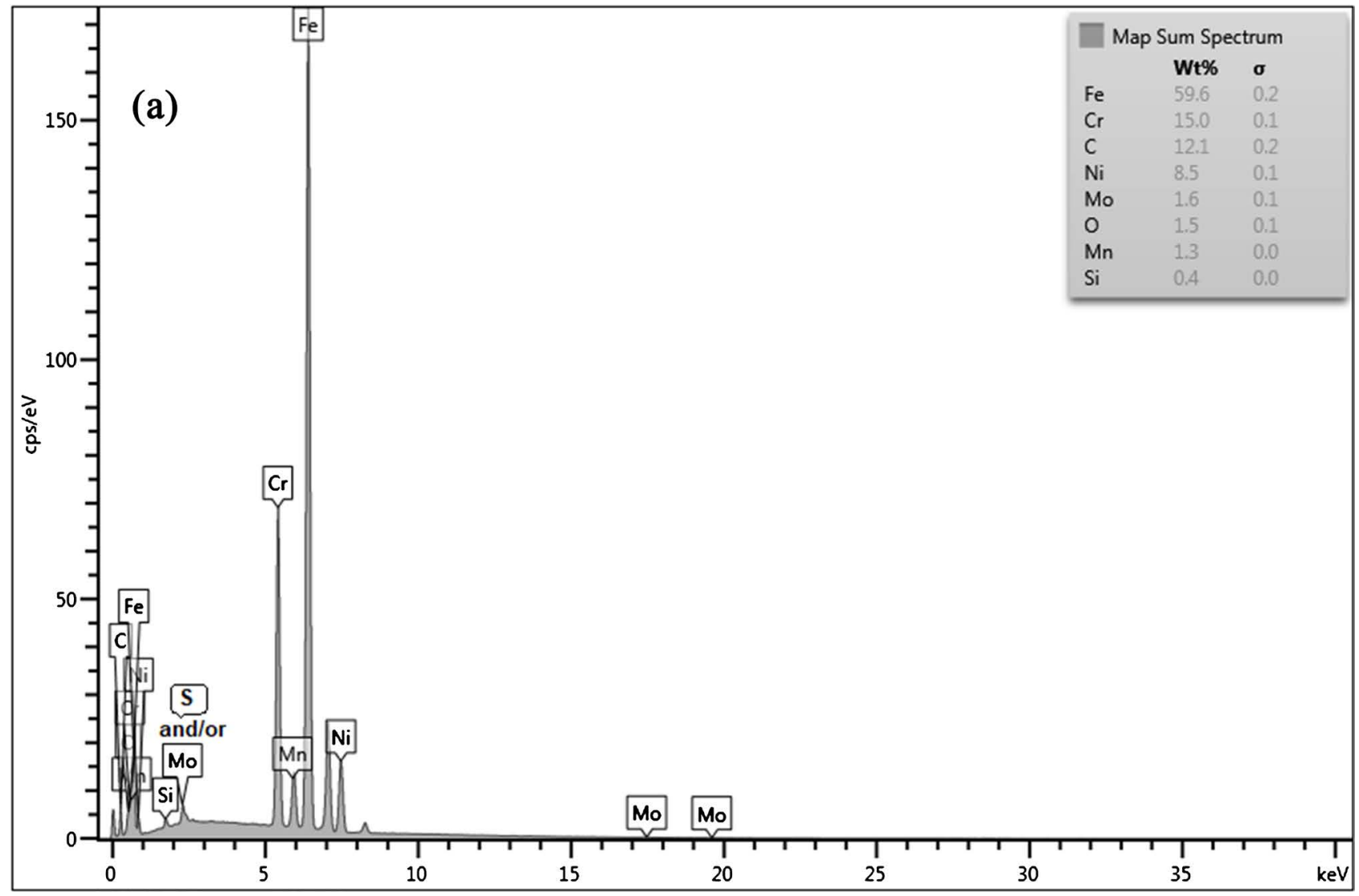

(b)
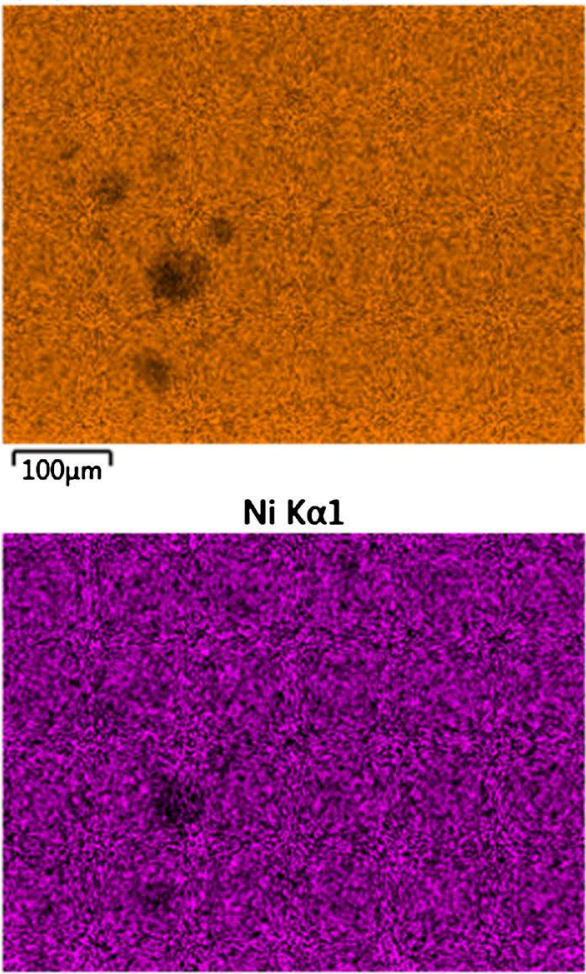

$\longdiv { 1 0 0 \mu \mathrm { m } }$
$\mathrm{Cr} \mathrm{K} \alpha \mathbf{l}$

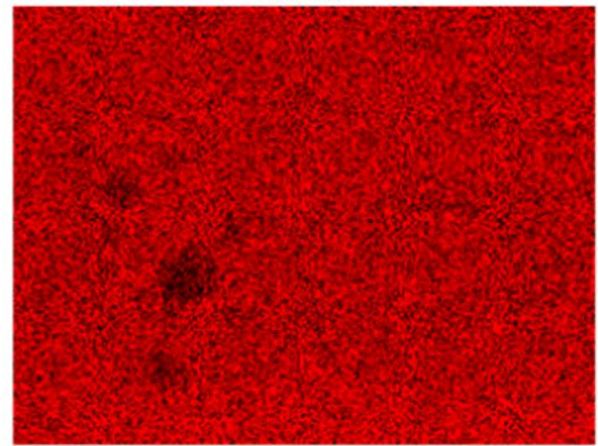

$\mathrm{Mn} \mathrm{Ka1}$

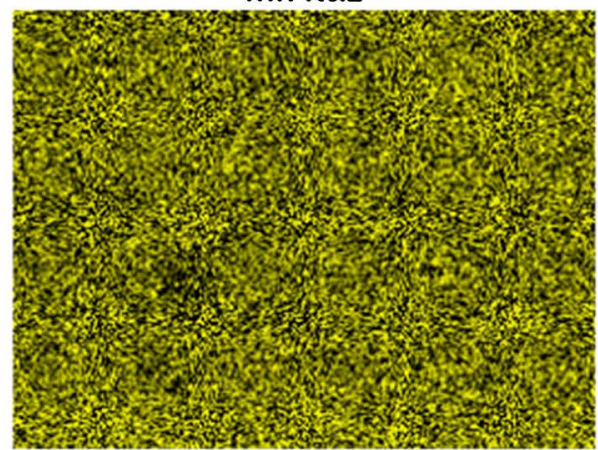

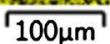



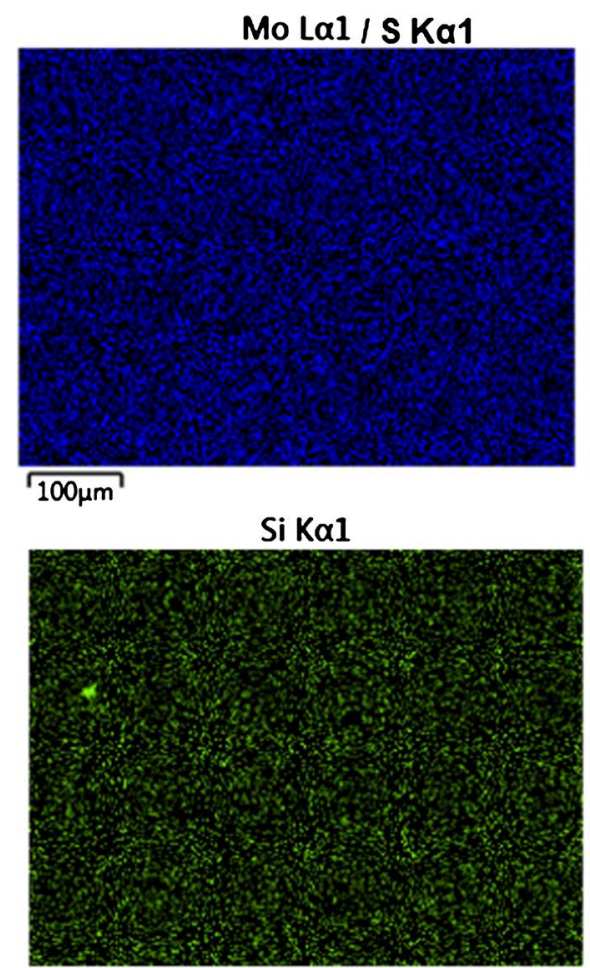

$100 \mu \mathrm{m}$

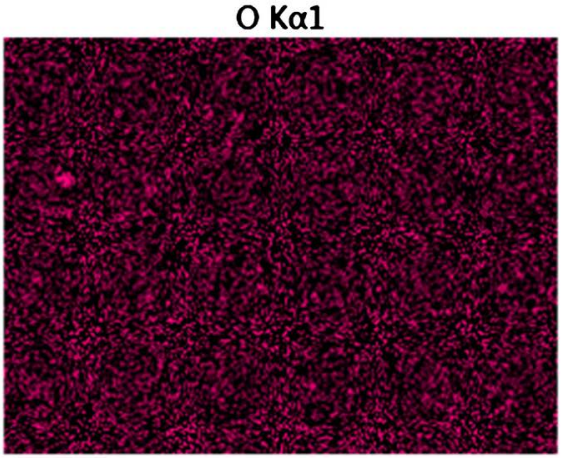

$\overline{100 \mu m}$

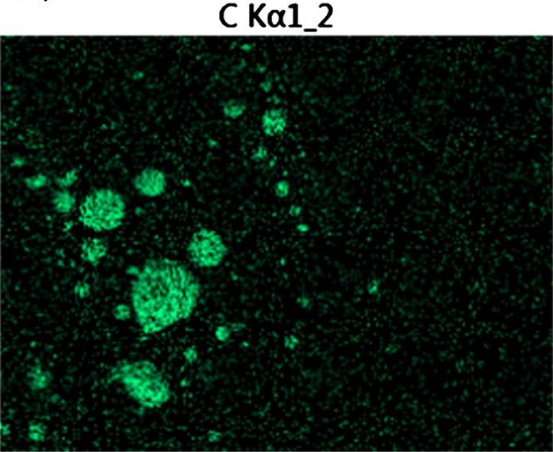

$100 \mu \mathrm{m}$

Figure S8. (a) EDS spectra and (b) Elemental mapping obtained by EDS AISI 304 stainless steel, immersed in a solution containing $50 \mathrm{mg} \cdot \mathrm{L}^{-1} \mathrm{HEDP}, 3.5 \mathrm{wt} \% \mathrm{NaCl}, 1 \mathrm{mmol} \cdot \mathrm{L}^{-1}$ $\mathrm{Na}_{2} \mathrm{~S}$ and $10 \mathrm{mg} \cdot \mathrm{L}^{-1} \mathrm{MgCl}_{2}$, after open circuit potential measurements. 